Ensayo

\title{
¿La mesa central de México es una provincia biogeográfica? Análisis descriptivo basado en componentes bióticos dulceacuícolas
}

\author{
Is the Mesa Central of Mexico a biogeographical province? \\ Descriptive analysis based on freshwater biotic components
}

\author{
Omar Domínguez-Domínguez ${ }^{1}$ y Gerardo Pérez-Ponce de León²,* \\ ${ }^{1}$ Laboratorio de Biología Acuática, Facultad de Biología, Universidad Michoacana de San Nicolás de Hidalgo. Edificio R , planta baja, Ciudad \\ Universitaria, 58030, Morelia, Michoacán, México. \\ ${ }^{2}$ Instituto de Biología, Universidad Nacional Autónoma de México. Apartado postal 70-153, 04510 México D. F., México. \\ *Correspondencia: ppdleon@ibiologia.unam.mx
}

\begin{abstract}
Resumen. En este ensayo se presenta un análisis del concepto de Mesa Central de México como una posible provincia biogeográfica. Esta región del país ha sido utilizada como referencia para describir la riqueza y distribución de una parte importante de la fauna ictiológica dulceacuícola, sin embargo, no es reconocida como provincia biogeográfica en ninguno de los esquemas actuales que, en su mayoría están basados en la composición de la biota terrestre. Se hace una reseña del surgimiento del concepto de Mesa Central como una provincia fisiográfica y contrastamos esta propuesta con los esquemas de regionalización basados en distintos atributos, tales como la fisiografía, la altitud, la hidrología, la geología, y la biogeografía. Concluimos que, si bien, Mesa Central es un concepto útil para referirse a la distribución de algunos elementos ictiofaunísticos, tal y como fue descrita originalmente no se circunscribe enteramente a ninguna de las regiones o provincias en las que se encuentra dividido el territorio nacional. Se discute el que esta región no puede tampoco considerarse como sinónimo del Eje Volcánico Transmexicano y que es posible que la no circunscripción de la zona a una regionalización biogeográfica se deba a que en general los elementos dulceacuícolas no han sido tomados en cuenta en la elaboración de dichos esquemas. Por último, señalamos la necesidad de realizar un análisis biogeográfico que integre la mayor cantidad de elementos bióticos acuáticos para poder determinar si efectivamente la fauna terrestre y la acuática están sujetas a los mismos procesos geobióticos.
\end{abstract}

Palabras clave: Mesa Central, peces de agua dulce, biogeografía, México, Goodeidae.

\begin{abstract}
This essay presents an analysis of the concept of Mesa Central of México as a potential biogeographical province. This region of México has been used as a reference for describing species richness and distribution patterns of the freshwater fish fauna. However, it has not been recognized as a biogeographical province in the available schemes which are mostly based on the composition of terrestrial biota. Here, we provide a historical sketch of the way the concept of Mesa Central arose in the literature as a physiographic province, and we provide a comparison with respect to the regionalization schemes of the Mexican territory, which are based on attributes such physiography, elevation, hydrology, geology and biogeography. We conclude that the Mesa Central, even though it represents a practical concept for establishing the distribution pattern of the fish fauna, in the way it was described originally cannot be circumscribed to any of the regions or provinces in which Mexico has been divided. We also argue that this geographical region cannot be considered as a synonym of the Transmexican Volcanic Axis biogeographical province, and also that it is possible that the fact that this area is not circumscribed to any regionalization scheme is due to the fact that freshwater elements have not been considered in the establishment of such biogeographical regions. We end by pointing out the need for a biogeographical analysis that integrates most of the freshwater elements in order to determine whether both the aquatic and terrestrial flora and fauna are driven by the same geobiotic processes.
\end{abstract}

Key words: Mesa Central, Freshwater Fishes, Biogeography, Mexico, Goodeidae.

Recibido: 24 febrero 2009; aceptado: 05 abril 2009 


\section{Introducción}

Por muchos años los biogeógrafos han propuesto sistemas de clasificación de la superficie terrestre basados en las áreas de distribución de los taxa, proponiendo el establecimiento de una regionalización biogeográfica como un sistema jerárquico que sea útil para categorizar las áreas en términos de su biota. México está posicionado entre la región Neártica y la Neotropical, por lo que desde el punto de vista biogeográfico ha sido de gran interés, para numerosos autores que han contribuido de manera importante al estudio de su biogeografía. En años recientes se ha intentado establecer una síntesis biogeográfica con la idea de entender cómo se estructuran espacialmente y cómo han evolucionado los componentes y elementos bióticos del territorio mexicano, a partir de las propuestas que utilizan enfoques descriptivos, o bien, análisis formales empleando distintas metodologías, ya sean éstas dispersalistas, fenéticas, panbiogeográficas o cladísticas (véase Morrone, 2005 y las referencias que ahí se citan). En el esfuerzo más importante que se ha logrado hasta el momento, Morrone (2005) analizó los esquemas de regionalización propuestos al menos en 17 trabajos publicados entre 1941 y 2003. Los esquemas de estas propuestas están basados primordialmente en elementos terrestres tanto de la fauna (insectos, vertebrados) como de vegetación, con muy pocos casos donde la fauna y/o vegetación acuáticas, o bien, elementos morfotectónicos fueran considerados (Rosen, 1976; Ferrusquia-Villafranca, 1990; Marshall y Liebherr, 2000). Más recientemente, Huidobro et al. (2006) presentaron un esquema de regionalización de la Zona de Transición Mexicana (sensu Morrone, 2004a, b) basado exclusivamente en la distribución de un grupo de peces duleacuícolas (Poeciliopsis spp., 22 especies), crustáceos decápodos (Pseudotelphusini, 34 especies) y angiospermas acuáticas (22 especies), concluyendo que los patrones que detectaron para éstos son congruentes con aquellos de taxa terrestres, tales como anfibios y reptiles, aves y mamíferos, lo que en opinión de los autores parecería indicar que estos patrones fueron inducidos por procesos geobióticos comunes.

De acuerdo con la regionalización propuesta por Morrone (2005), México contiene 14 provincias agrupadas en 2 regiones (Neártica y Neotropical) y una zona de transición. Esta última, en un sentido restringido (Morrone, 2004a, 2004b), contiene a su vez 5 provincias: Eje Volcánico Transmexicano (EVT), Sierra Madre Occidental (SMO), Sierra Madre Oriental (SMOr), Sierra Madre del Sur (SMS) y Cuenca del Balsas (CB). En este contexto, un área geográfica que ha sido reconocida principalmente en diferentes trabajos ictiofaunísticos y parasitológicos es la denominada Mesa Central de México, que en el esquema propuesto por Morrone (2005) está considerada como sinónimo o queda contenida dentro de la provincia del EVT. De acuerdo con Morrone (2005), la provincia del EVT se ubica en el centro de México, en los estados de Guanajuato, Distrito Federal, Estado de México, Jalisco, Michoacán, Puebla, Oaxaca, Tlaxcala y Veracruz y corresponde básicamente al sistema montañoso del Eje Neovolcánico Transversal, constituyendo el límite austral del Altiplano Mexicano. Corona et al. (2007) demostraron recientemente que esta provincia no representa una unidad biogeográfica natural, pues tal y como ocurre con otras áreas de la Zona de Transición Mexicana, esta zona es el resultado de eventos de hibridación biótica.

El objetivo principal de este ensayo es entonces el de describir los elementos históricos que determinaron el surgimiento del concepto de Mesa Central y con base en ello analizar su circunscripción en relación con distintos esquemas de regionalización que se han propuesto para México basados tanto en la composición biótica como en otros criterios, discutiendo si la Mesa Central podría representar como tal una unidad biogeográfica que pudiera ser considerada incluso como una provincia biogeográfica, en virtud de que, en principio, está reconocida como una provincia ictiofaunística. Así, el concepto de Mesa Central surge para describir la distribución de componentes faunísticos dulceacuícolas, principalmente peces; incluso, algunos parasitólogos han utilizado tradicionalmente el término para dar una connotación geográfica a sus hallazgos (Pérez-Ponce de León et al., 2001, Pérez-Ponce de León, 2003; Pérez-Ponce de León y Choudhury, 2005). De hecho, en un trabajo de gran importancia publicado recientemente (Miller et al., 2005), la Mesa Central se considera una de las 8 provincias ictiofaunísticas en que se divide el territorio mexicano. A pesar del reconocimiento de que los límites establecidos para la Mesa Central provienen de criterios fisiográficos, Minckley et al. (2005) estiman que la distribución de la ictiofauna es suficientemente característica para darle identidad como región independiente, al margen de reconocer las relaciones que esta fauna tiene con aquella de las provincias aledañas, al referirse a su origen y patrones de diversificación a través de conexiones ancestrales entre distintas cuencas hidrológicas. Por último, en este ensayo también utilizamos la información disponible para discutir si los esquemas de regionalización basados en elementos bióticos terrestres serán concordantes con los elementos bióticos acuáticos que apoyen o refuten la hipótesis de que los patrones serían resultado de procesos geobióticos comunes. Todo lo anterior tiene como propósito contribuir con más elementos de análisis para abordar la regionalización biogeográfica de México y con una base estandarizar la 
terminología utilizada por diferentes autores al referirse a esta importante zona del país desde el punto de vista biogeográfico.

\section{¿Qué es la Mesa Central?}

Miller y Smith (1986) señalaron que el centro de México es una región con una compleja historia geológica y una configuración superficial diversa y que su principal componente fisiográfico es la denominada Mesa Central, una región localizada en el extremo sur del Altiplano Mexicano y que comprende el Cinturón Volcánico Transmexicano (o EVT), estando sus límites, con la excepción de su parte norte, bien establecidos; al sur, por la depresión del Balsas, al este por la sierra Madre Oriental y al oeste, por la sierra Madre Occidental. Además, señalaron que el sistema Lerma-Santiago representaba la mayor cuenca hidrológica de la Mesa Central y que existían algunos tributarios de cuencas mayores dentro de esta región, como la del río Pánuco en el este y la del Balsas en el sur (Barbour, 1973). En su historia geológica, la Mesa Central ha tenido una serie de fragmentaciones hidrográficas en las cuales grandes lagos y ríos de bajos gradientes han sido componentes importantes. Este factor ha determinado el elevado nivel de diversificación entre los vertebrados de la región, especialmente aquellos confinados a ambientes acuáticos continentales, como resultado de repetidos eventos de vicarianza y dispersión. Desde el punto de vista biogeográfico, esta zona del centro de México es de gran importancia, pues para algunos autores representa la zona limítrofe entre las regiones biogeográficas Neártica y Neotropical (Marshall y Liebherr, 2000, Pérez-Ponce de León, 2003), actuando como zona de transición. La definición de Mesa Central (también llamada Mesa de Anáhuac o Mesa Central del Sur) que se encuentra en la Enciclopedia Británica, un texto de amplia difusión que no hace referencia a una regionalización biogeográfica, indica que es un altiplano alto en el centro de México, mismo que comprende la sección sur del Altiplano Mexicano, y que se extiende del sur de Zacatecas a la región Bajío, con una elevación que varía de los 1800 a los 2300 m snm, siendo considerablemente más alta y húmeda que la Mesa del Norte. La circunscripción de esta región hace referencia principalmente a los componentes hidrográficos que existen dentro de ésta, tal y como se muestra en la figura 1, donde Rojas-Rabiela (2004) presenta un mapa de las cuencas endorreicas de la Mesa Central, pero no establece los límites de la misma (Fig. 1).

Como se indicó anteriormente, el término de Mesa Central ha estado intrínsecamente asociado al estudio de los componentes dulceacuícolas de las cuencas hidrológicas del centro de México, particularmente de los peces, y contribuciones tan importantes en este sentido como las de Barbour (1973), Barbour y Miller (1978), Echelle y Echelle (1984), Miller y Smith (1986) y Barbour y Miller (1994) hacen referencia al término Mesa Central al describir la historia biogeográfica de los peces dulceacuícolas de la región. Para entender la delimitación precisa y el origen mismo del concepto de Mesa Central, a continuación se presenta un bosquejo histórico de algunos de los esquemas de regionalización que se han realizado en México tomando en consideración para ello a los peces dulceacuícolas, desde los trabajos pioneros de Meek y Regan a principios del siglo pasado, hasta la propuesta como tal de la región de la Mesa Central por West (1964a, 1964b).

Meek (1904), al estudiar la fauna ictiológica dulceacuícola de México, realizó una revisión de la topografía e hidrografía mencionando que gran parte de México estaba compuesto por un gran altiplano con una altitud de 914 a 2438 metros por encima del nivel del mar. En su estudio, Meek refiere que al norte de la cuenca del río Balsas, el Altiplano Central está drenado por el río Lerma, conocido como el río Grande de Santiago al dejar el lago de Chapala, y que el Valle de México es una cuenca independiente, lo cual se evidencia por la naturaleza de su ictiofauna, señalando que quizás la antigua cuenca del Valle de México en el pasado drenaba el río Lerma y que el límite norte de su cuenca estaba en Zacatecas.

Otro autor que tuvo una gran influencia en la descripción de la ictiofauna mexicana fue Regan (1906-1908), quien a pesar de la poca información que existía en esa época hizo referencia a la distribución y biogeografía de los peces de México y Centro América, señalando una regionalización con base en la distribución de las familias de peces. Fue el primero en reconocer que la cadena montañosa que cruza el centro de México, desde Colima hasta Veracruz (Eje Neovolcánico Transversal $=$ EVT), es la frontera entre la ictiofauna neártica y la neotropical. Señaló que esta cadena montañosa parecía ser un obstáculo para que la fauna neotropical alcanzara las tierras altas del Altiplano Mexicano, y que los peces neotropicales sólo se dispersaban hacia latitudes arriba de dicha cadena montañosa por las tierras bajas que lo bordean en las planicies de la costa Atlántica y Pacífica. Una situación similar ocurría con la ictiofauna neártica, siendo dicha cadena montañosa una barrera con excepción de algunas especies que se distribuían más al sur de ésta. Asimismo, con base en la distribución de las diferentes familias de peces, propuso la idea de provincias biogeográficas (Fig. 2).

Regan señaló que existían peces de las regiones Neártica y Neotropical. Con la información taxonómica que se tenía en ese momento, habló de 3 subregiones de la Región Neártica, desde Alaska hasta México, siendo la más sureña la del río Grande (= Río Bravo), la cual incluía 


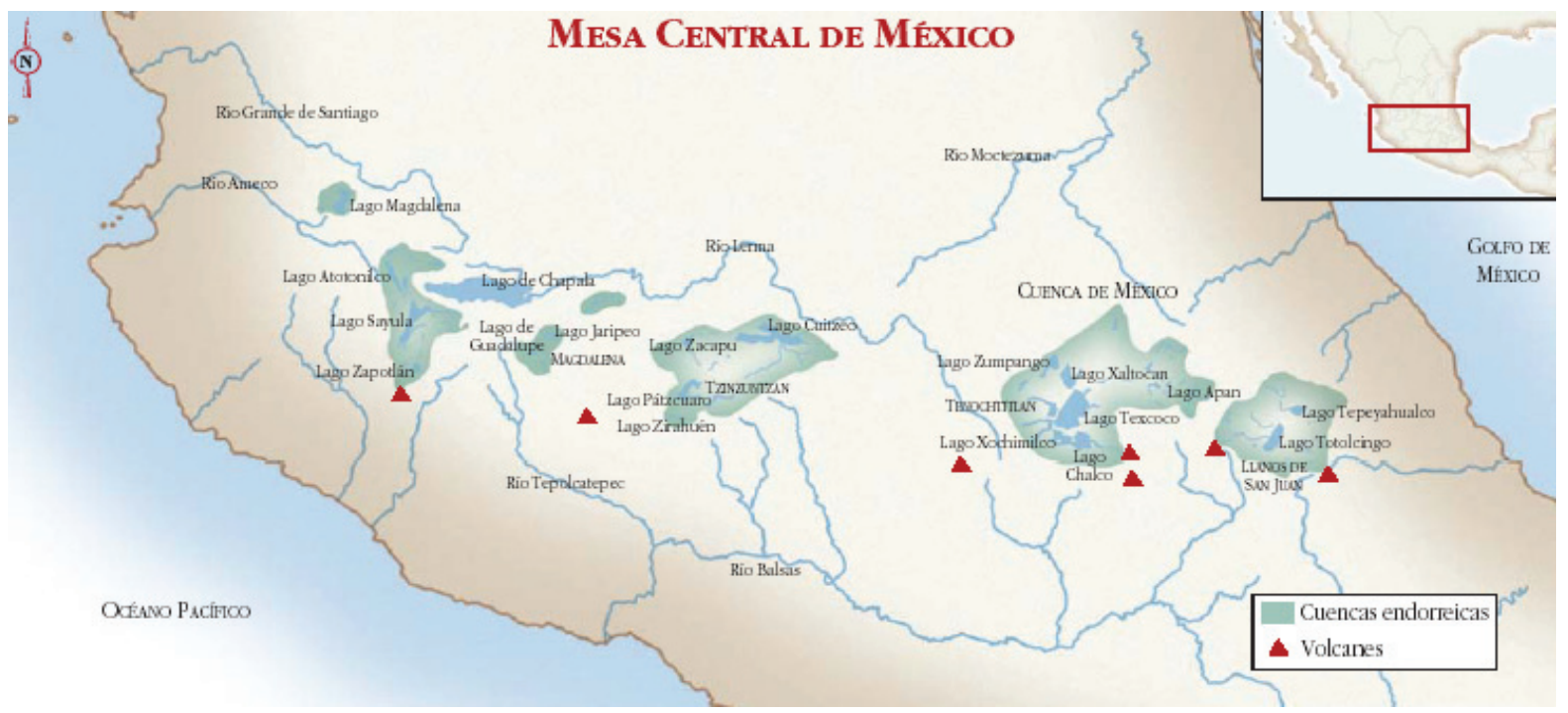

Figura 1. Cuencas endorreicas de la Mesa Central de México. Modificado de Rojas-Rabiela (2004).

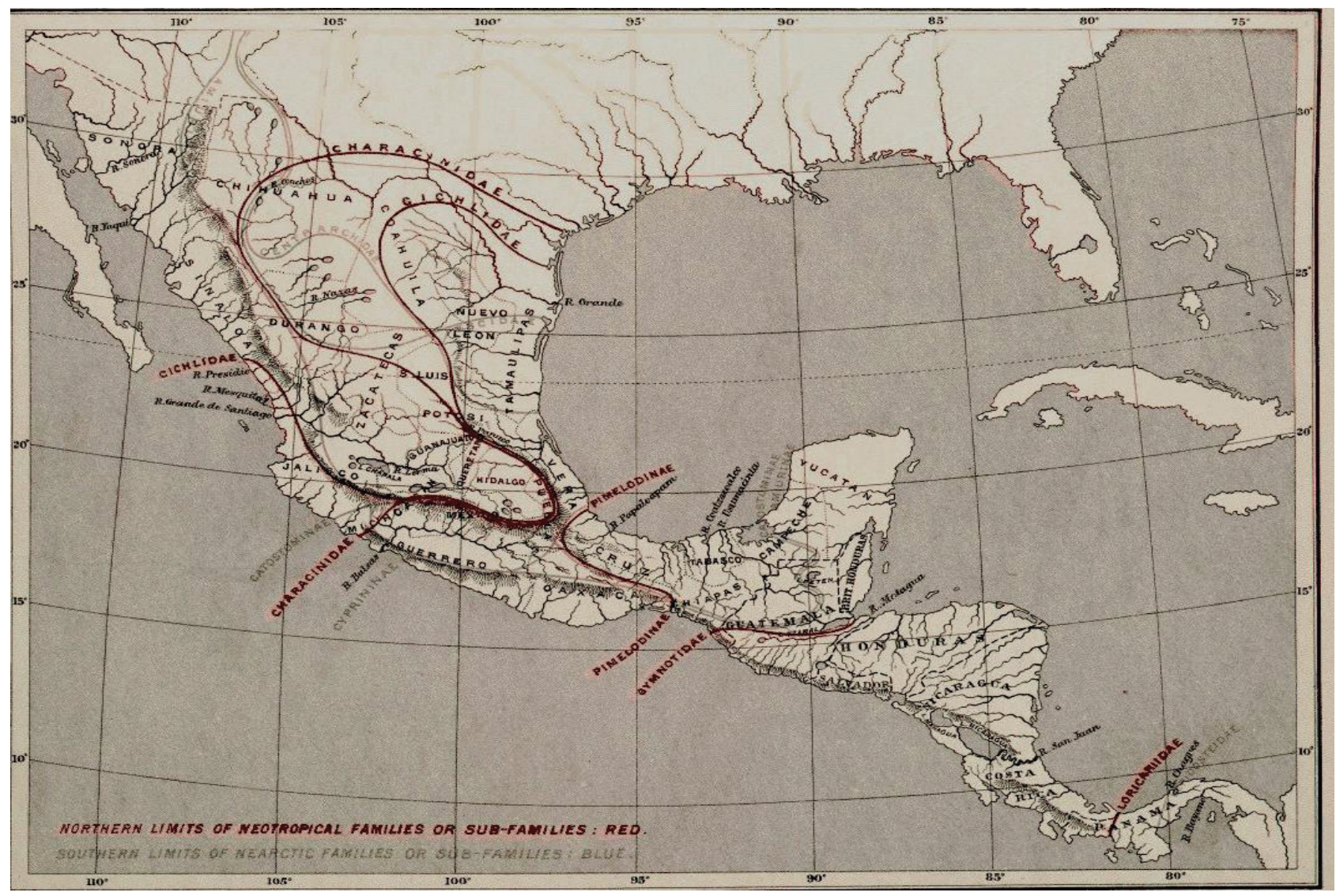

Figura 2. En líneas rojas, límite norte de las familias y subfamilias de peces neotropicales y líneas grises, límite sur de las familias y subfamilias de peces neárticos. Modificado de Regan (1906-1908). 
los ríos al norte del sistema Lerma, junto con los ríos de Tamaulipas y norte de Veracruz en la costa del Atlántico. Algunos ríos de Chihuahua y Durango fluyen en dirección al río Grande (= río Bravo), pero nunca llegan a él y terminan en lagos que cambian mucho en sus dimensiones de acuerdo con la temporada, sin embargo, se cree que estos sistemas (incluyendo el río Mezquital) en un pasado fluían al sistema del río Grande (= río Bravo). Dada la complejidad de la zona, se refirió a provincias. Además, este autor mencionó que debido a lo peculiar de su composición ictiófaunística, el sistema del río Lerma (justo antes de las cascadas e incluyendo el Río San Juan, tributario del río Pánuco y los lagos interiores de los estados de Michoacán y México), debía considerarse como una subregión de la región Neártica, misma que incluía grupos de peces tales como Characodontinae (= Goodeidae) y Atherinidae (=Aterinopsidae), carecía de elementos representantes de la fauna neotropical y contenía representantes de la fauna neártica (Cyprinidae), muchos de ellos endémicos.

Por su parte, la región Neotropical estaba caracterizada principalmente por los siluriformes y carácidos. En esta región incluyó también 3 divisiones principales denominadas Patagoniana, Brasileña y Centroamericana. Esta última estaba caracterizada por la presencia de escasos representantes neárticos y por el peculiar desarrollo de las familias Cichlidae y Cyprinodontidae. A su vez, dividió de manera provisional esta subregión en 4 provincias: 1) Provincia del río Balsas que estaba caracterizado por la presencia de grupos neárticos (v. gr. Ameiurus (=Ictalurus) y Notropis) y por la escasez o ausencia de especies típicas de América Central (Cichlidae, Pimelodidae, Poecilidae). 2) Provincia del río San Juan que incluía la zona desde el lago Managua y el río San Juan, caracterizado por lo peculiar de los miembros de la familia Cichlidae, 3) la provincia del Sistema Papaloapan, ubicada al norte de la Provincia del río San Juan, representado por miembros de la fauna neártica como Ameiurus (=Ictalurus), Ictiobus y Lepisosteus, y particularmente por un número importante de peces de las familias Cichlidae y algunos miembros de la familia Cyprinodontidae. Esta fue denominada como la provincia Guatemala, y 4) la provincia del Itsmo, representada principalmente por Panamá y Costa Rica.

Sin embargo, no fue sino hasta que Wanchope y West (1964) editaron el Handbook of Middle American Indians cuando se realizó el primer trabajo sobre Centro América abordando aspectos de la historia geológica y paleogeográfica, de la configuración superficial y la asociación geológica, y de la hidrografía, cuando el término Mesa Central de México fue establecido, dado que estos autores consideraban que México, desde su área central, pertenecía a esta región.

Maldonado-Koerdell (1964) dividió Centro América en provincias geológicas. El centro del territorio Mexicano contenía 5 de estas provincias, a las que denominó: 1) Sierra Madre Occidental, 2) Alto Altiplano Central, 3) Planicie Costera del Golfo de México, 4) Eje Neovolcánico, y 5) Sur de la Sierra Madre (Fig. 3). Dicha división está justificada señalando que las diferentes provincias corresponden con las principales características geomorfológicas y especialmente a unidades estructurales.

Al describir la configuración superficial de Centro América y la historia geológica asociada a ésta, West (1964a) hizo referencia por primera vez al concepto de Mesa Central. y propuso entonces las siguientes regiones fisiográficas para México, que en principio son muy parecidas a las provincias geológicas presentadas por Maldonado-Koerdell (1964; Fig. 3), pero en las cuales se encuentra una uniformidad en características superficiales (Fig. 4):

I. Altiplano Mexicano y escarpados adyacentes.

A. Altiplano superficial.

1. Mesa Central (altiplano meridional) y Sierra Neovolcánica.

2. Mesa del Norte (altiplanicie septentrional)

a. Área alta al oeste del basin and range.

b. Área baja central desértica.

B. Montañas y escarpados asociados

1. Sierra Madre Oriental.

2. Sierra Madre Occidental.

3. Escarpados del sur (de la Sierra Neovolcánica)

II. Península de Baja California.

III. Tierras Bajas Costeras adyacentes al Altiplano Mexicano.

A. Tierras bajas del Pacífico

B. Tierras Bajas del Golfo

IV. Tierras del Sur de México.
A. Depresión del Balsas-Tepalcatepec.
B. Tierras altas del Sur de México.
C. Istmo de Tehuantepec.
D. Tierras altas de Chiapas.

Es precisamente aquí donde aparece por primera vez el término de Mesa Central en la literatura. Retomamos de West (1964a) la mayor parte de la descripción de la zona en términos de su fisiografía, pues ésta es relevante para caracterizar la Mesa Central como una región y discutir, más adelante, si es o no una región biogeográfica:

La región fisiográfica más grande de Centro América es el denominado Altiplano Mexicano, el cual se extiende desde la actual frontera entre México y Estados Unidos hacia el sur, aproximadamente a la latitud de la ciudad de México. Las elevaciones son mayores en el sur del Altiplano, formando una de las zonas altas tropicales más grandes del mundo. Gran parte del Altiplano está por encima de los 2000 m 


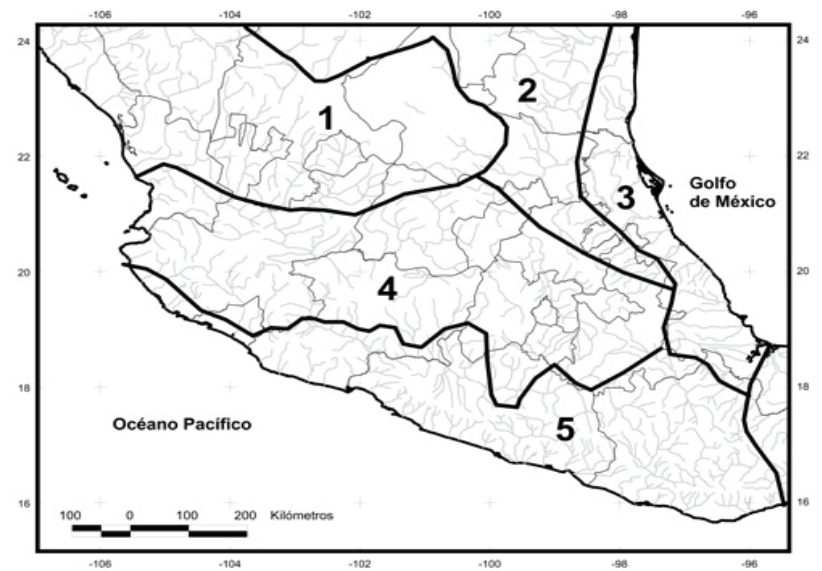

Figura 3. Principales provincias geológicas del Centro de México: 1. Sierra Madre Occidental, 2. Alto Altiplano Central, 3. Planicie Costera del Golfo de México 4. Eje Neovolcánico, y 5. Sur de la Sierra Madre. Modificado de Maldonado-Koerdell (1964).

snm, la elevación va decreciendo hacia el norte hasta llegar a aproximadamente $1000 \mathrm{~m}$ snm en los límites de la frontera entre ambos países. Fisiográficamente el Altiplano Mexicano consta de 2 partes, la superficie de las tierras altas y el sistema montañoso que las bordea. El sistema de montañas y escarpados adyacentes a éste son la sierra Madre Oriental, la sierra Madre Occidental y el Eje Volcánico Transversal.

Asimismo, West (1964a) señaló que la superficie del Altiplano, a su vez, estaba compuesta de 2 partes, las cuales describió desde el punto de vista fisiográfico:

1. Mesa del Norte o Altiplanicie Septentrional, que cubre 2 tercios áridos y semiáridos del altiplano en el norte y que se extiende desde la frontera entre México y Estados Unidos, hasta aproximadamente las latitudes de las ciudades de Aguascalientes y San Luis Potosí. Es una extensa área de plegamientos y fallamientos montañosos separados y medio sumergidos por profundos depósitos aluviales que forman extensas cuencas planas. Usualmente el norte de esta región es considerada una extensión de la topografía del basin and range de Estados Unidos. Al menos dos rasgos fisiográficos mayores pueden distinguirse en la Mesa del Norte: a) una área semiárida de conos volcánicos separados por altas cuencas aluviales adyacentes a la Sierra Madre Occidental, y b) la zona central baja, la parte este de la meseta y las áreas semiáridas con características de tierras desérticas y cuencas interiores. Dichas áreas se extienden del este de la sierra Madre Occidental y las cercanías del suroeste de Zacatecas al noroeste del distrito de Casa Grandes en Chihuahua. Como elementos hidrológicos incluye el paleolago de

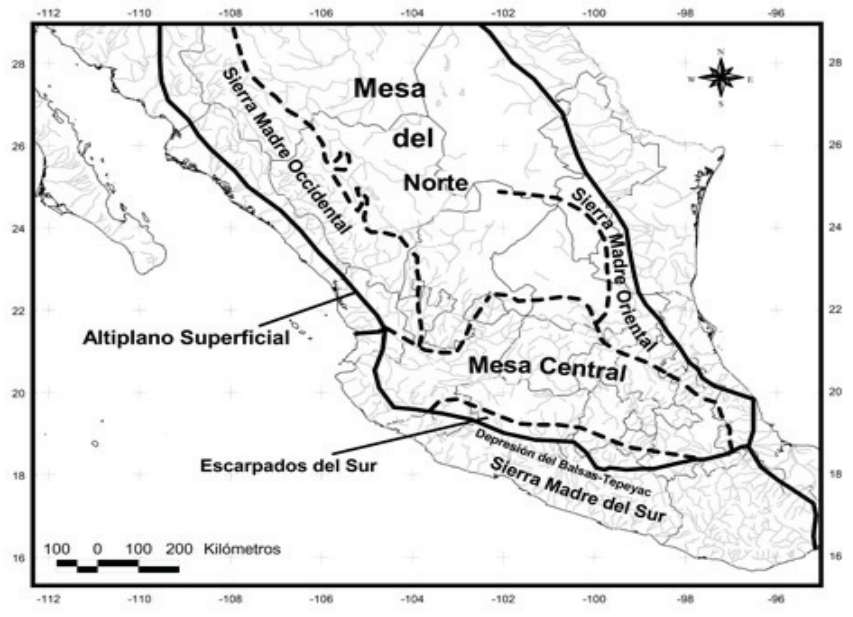

Figura 4. Regiones Fisiográficas de México, la línea sólida se refiere al Altiplano Superficial, la línea punteada a las fronteras de la Mesa Central, Sierra Madre Oriental y Sierra Madre occidental. Modificado de West (1964a).

Santiaguillo, el suroeste de Zacatecas, el norte de San Luis Potosí, los paleolagos de Parras, la recientemente desecada laguna del Mayran y las planicies del Guadiana.

2. Altiplanicie Meridional, Altiplano Volcánico o Mesa Central, que cubre el último tercio, en el sur, y que se caracteriza por ser una zona más alta y húmeda. Esta zona es una región con características volcánicas por excelencia. La actividad volcánica se presentó principalmente durante el Pleistoceno y en algunas localidades continúa hasta la actualidad, lo cual ha influenciado en gran medida su configuración actual. Cubriendo el borde sur del Altiplano se encuentra una serie de altos volcanes, cuyo conjunto es conocido como el Eje Volcánico Transversal. Esta región incluye los volcanes Pico de Orizaba, Cofre de Perote, Malinche, Popocatepetl, Ixtlacihuatl, Nevado de Toluca, Tancítaro, y Volcán de Colima (Fig. 5). Los picos mayores a $3800 \mathrm{~m} \mathrm{snm}$ muestran evidencia de las glaciaciones del Pleistoceno y recientes. Dentro de la zona se pueden observar numerosas áreas de fracturas y grabens. También se encuentra un gran número de cuencas y cuerpos de agua de diversos tamaños (tanto endorreicos como exorreicos), formados en su mayoría por taponamiento de ríos debido a la actividad volcánica. Dichos lagos varían en altitud de los 1400 a los $2600 \mathrm{~m}$ snm. Asimismo, se observa un gran número de sedimentos lacustres que varían en extensión y profundidad, lo que hace suponer la existencia de un gran número de lagos que fueron secados por la acumulación de sedimentos.

Los límites este y oeste del Altiplano Mexicano están dados por sus bordes altos y acantilados, lo cual incluye la Sierra Madre Oriental que es un delgado cinturón 


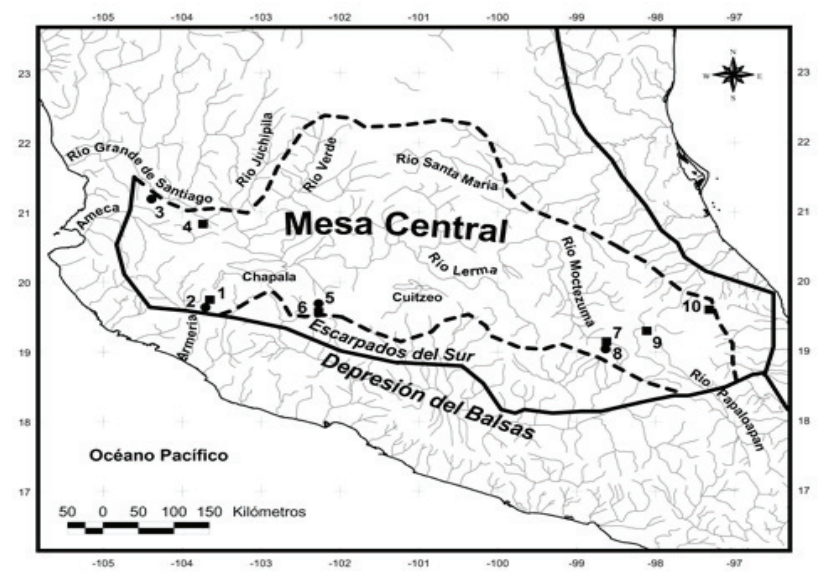

Figura 5. La Mesa Central de México. En líneas punteadas los limites de la Mesa Central. En círculos se representan volcanes activos en tiempos históricos, en cuadros se representan los volcanes extintos. Modificado de West (1964a).

\begin{abstract}
montañoso que corre de norte a sur. También se reconoce a la Sierra Madre Occidental como el borde oeste del Altiplano Mexicano, misma que se extiende a lo largo de $1200 \mathrm{~km}$ desde la frontera entre México y Estados Unidos, hasta el Río Santiago en el estado de Jalisco, aunque se ha propuesto que el límite sureño está en el Río Mezquital en el sur del estado de Durango. La última parte se denomina Escarpados del Sur del Eje Neovolcánico y representa el límite sur del Altiplano Mexicano, en la denominada Depresión del Balsas. Los arroyos y ríos que drenan la Depresión del Balsas han erosionado grandes cañones en muchas partes de la zona más escarpada, especialmente en las cercanías de la sierra de Mil Cumbres.
\end{abstract}

En el mismo año, West (1964b) presentó una regionalización de las zonas naturales de América Central basada en la vegetación y el clima, dividiendo la zona en 3 regiones naturales: Tierras secas del norte de México, Tierras tropicales frías y altas, y Tierras tropicales bajas y cálidas. Dentro de las segundas se encuentra precisamente la denominada Mesa Central, misma que ha sido caracterizada como la región de tierras altas tropicales más larga y la más significativa culturalmente de América Central. Uno de los rasgos representativos de ésta zona son los sedimentos lacustres entre las colinas volcánicas y sierras.

Reconocimiento de la Mesa Central para la descripción de patrones biogeográficos de la ictiofauna dulceacuícola

Inspirados en las ideas expresadas por los autores anteriormente citados, algunos ictiólogos estudiaron con cierto detalle la biogeografía de peces dulceacuícolas de la Mesa Central de México. Quizás el trabajo de Barbour (1973) sea el más representativo, siguiéndole algunas otras contribuciones que complementaron la descripción de la Mesa Central con base en la distribución de la fauna ictoiológica en relación con los elementos de la historia geológica de la región. Barbour (1973) describió la biogeografía de las especies del género Chirostoma, recapitulando dentro de este estudio el concepto de Mesa Central de acuerdo con las ideas de West (1964a, b). Barbour (1973) consideró el Altiplano Mexicano dividido en 2 partes, la primera, denominada Mesa del Norte, se extendía desde el río Bravo hasta aproximadamente la latitud de las ciudades de Aguascalientes y San Luis Potosí, caracterizada como una región árida o semiárida con altitudes que varían entre 600 y $1200 \mathrm{~m}$ snm al sur de San Luis Potosí, mientras que la segunda, la Mesa Central, se caracterizaba por presentar valles intermontanos más estrechos y más fértiles y montañas de origen volcánico cuya altitud variaba de1800 a poco más de 3000 m snm. Asimismo, Barbour (1973) reconoció los límites de la Mesa Central, con la sierra Madre Oriental en el margen este (continuación de las Montañas Rocallosas, extendiéndose a través de los estados de Coahuila, Nuevo León, Tamaulipas, y el este de San Luis Potosí, Hidalgo y Puebla), estando formado el límite oeste por la sierra Madre Occidental, extendiéndose a través de los estados de Sonora, Sinaloa, Chihuahua, Durango, Nayarit y Jalisco, y el límite sur, por el Cinturón Volcánico Transmexicano, el cual se extendía en dirección este-oeste entre los paralelos $19^{\circ}$ y $20^{\circ}$, región que durante el Cretácico medio estuvo inundada por una transgresión marina, el Portal del Balsas, la cual conectaba el geosynclinal mexicano con el océano Pacífico (Maldonado-Koerdell, 1964). Al parecer el vulcanismo comenzó durante el Cretácico tardío, pero la actividad volcánica que ha generado en mayor medida la configuración actual comenzó en el Terciario medio, creciendo durante el Pleistoceno y continuando incluso hasta nuestros días.

En el mismo trabajo, Barbour (1973) presentó una caracterización de los cuerpos de agua de la Mesa Central, que a continuación se presenta, donde habitaban fundamentalmente las especies de los géneros Chirostoma y Poblana a quienes en su conjunto se les conoce como charales o pescados blancos.

Llanos de Puebla. Incluye los lagos y las numerosas formaciones lacustres localizadas al noreste de la ciudad de Puebla, las cuales aparentemente fueron formadas en el Pleistoceno. Remanentes salinos de los grandes lagos antiguos se encuentran en el centro de la cuenca, al este del Carmen, en el estado de Tlaxcala. Al noreste de la ciudad de México, en las cercanías de Apan, Hidalgo se 
encuentran fondos lacustres similares.

Valle de México. Está ubicado en un graben de dirección norte-sur, cuyo origen se ha trazado en el Terciario medio. El fallamiento se inició en ese tiempo y probablemente la cuenca fue drenada hacia el sur a lo que ahora es la cuenca del río Balsas, finalizando en el Mioceno, cuando la actividad volcánica diezmó esta salida y se inició un ciclo de fuerte erosión.

Cuenca del río Lerma. Barbour (1973) dividió esta zona en 4 partes: a) valle de Toluca, b) cuenca de Maravatío, c) Bajío, y d) lago de Chapala. Incluyó también las cuencas interiores de los lagos Atotonilco, San Marcos, Sayula, Zacoalco, Cajatitlan y Zapotlán, todos ellos lagos muy someros con fuertes variaciones de nivel.

Cuencas del oeste. Aquí se incluyen 3 lagos del oeste de Jalisco y Nayarit (Santa María, San Pedro Lagunillas y Juanacatlán) cuya ictiofauna indica una conexión ancestral con el río Lerma.

Valle de Tocumbo. Entre las ciudades de Cotija y Tocumbo; en la actualidad, la cuenca está formada por la presa de San Juanico y el lago de Magdalena, hoy seco. Aparentemente, dicha zona contenía un antiguo tributario del lago de Chapala que fue taponado por un flujo de lava, creando el lago de San Juanico; posteriormente, este lago fue extendido por la construcción de una represa, vertiendo sus aguas hacia el sur, a la cuenca del río Balsas.

Lagos de Zirahuén, Pátzcuaro y Cuitzeo. Lagos formados por el represamiento de un tributario del río Lerma, siendo el de Cuitzeo un lago muy somero, con poca vegetación y se considera decadente. El lago de Pátzcuaro está considerado como un lago maduro, con profundidades hasta de $15 \mathrm{~m}$, y una variada y rica flora acuática. El lago de Zirahuén, el más profundo (hasta 46 metros), es pequeño y se le considera un lago joven, con poca vegetación acuática marginal.

Tributarios del río Santiago. El río Santiago nace en la porción este del lago de Chapala, el cual cae rápidamente en las cascadas de Juanactalán para posteriormente correr por un cañón hacia el océano Pacífico. Sus principales tributarios son, de este a oeste, los ríos Verde, Juchipila, Bolaños, y Huaynamota.

Más de una década después, Miller y Smith (1986) realizaron una revisión del origen y zoogeografía de los peces del centro de México. Dentro de esta región incluyeron las cuencas y cabeceras de tributarios de los ríos Pánuco y Papaloapan en la vertiente del Atlántico, mientras que, para la vertiente del Pacífico incluyeron las cuencas del río Lerma-Santiago, del río Verde-Atoyac y las cuencas que se encuentran entre el río Lerma-Santiago y los Llanos de Puebla en el Altiplano Mexicano. Estos autores situaron el límite norte del centro de México justo al sur del río Bravo, cerca de los $23^{\circ}$ de latitud, mientras que el sur lo delimitaron a los $18^{\circ}$ por el Atlántico y los $16^{\circ}$ por el Pacífico y refirieron la presencia de la Mesa Central dentro de la región. Asimismo, señalaron el sistema LermaSantiago como la cuenca hidrográfica más significativa del centro de México, estando representada por 3 grupos de peces autóctonos, la familia Atherinopsidae, la familia Goodeidae y el género Algansea (Cyprinidae). Los autores mencionaron que el río Lerma drenaba la mayor parte de la Mesa Central de México, haciendo notar que la distribución de los peces que caracterizaba esta zona correspondía más a los límites geológicos de la Mesa Central que a los límites hidrográficos del río Lerma y sus tributarios. La circunscripción de la Mesa Central presentada en este trabajo es, también, aquella de West (1964a, b). Asimismo, Miller y Smith (1986) refieren algunos aspectos de la historia geológica de la región al señalar que la sierra Madre Oriental, la cual bordeaba la Mesa Central en su porción noreste, era el resultado de episodios geológicos de levantamientos y deformaciones que ocurrieron en el Eoceno temprano. La erosión en la porción este de dichas montañas produjo detritus que actualmente componen la planicie costera del Golfo. En la porción oeste de estas montañas, los sedimentos erosionados se acumularon en las cuencas y las áreas adyacentes de la Mesa Central, contribuyendo así al levantamiento del altiplano de la Mesa Central. La formación del fuerte relieve de la porción oeste de la Mesa Central comenzó con la expulsión de rocas de gran parte de la sierra Madre Occidental, fenómeno que ocurrió entre los 20-30 y hasta los 9.5-4.6 millones de años. Por ello, relatan que la Mesa Central fue generada en parte por la acumulación de productos volcánicos expulsados por subsecuentes episodios volcánicos que comenzaron en el Mioceno, intensificándose en el Pleistoceno e incluso, como ya se describió anteriormente, continúan hasta nuestros días.

Al establecer algunos aspectos de la evolución de varios species flocks (= grupos monofiléticos que incluyen especies cercanamente relacionadas que habitan en un mismo ecosistema) de aterinópsidos de la Mesa Central de México utilizando un análisis de electroforesis y métodos fenéticos y cladísticos, Echelle y Echelle, (1984), revisaron nuevamente el concepto de Mesa Central y realizaron una sinopsis geológica, basándose en los trabajos de Barbour (1973) y Smith (1980), quienes a su vez se habían basado en West (1964a,b). Echelle y Echelle (1984) mencionaron que la Mesa Central es la porción más sureña del Altiplano Mexicano y reiteraron que el sistema Lerma-Santiago es la cuenca más importante dentro de la Mesa Central y también que ésta posee algunas cuencas endorreicas, las cuales incluyen el Valle de México y Llanos de Puebla en el este, los lagos Santa María y Juanacatlán en el oeste, el valle de Tocumbo y los cercanamente relacionados lagos 
de Cuitzeo, Pátzcuaro y Zirahuén. Sus resultados muestran que el género Menidia, de origen marino, comparte un ancestro común con las especies de los géneros Chirostoma y Poblana que habitan en cuerpos de agua de la Mesa Central y sugieren que todos ellos conforman un trazo biogeográfico al que denominan "del altiplano" (que aparentemente se basa en el método panbiogeográfico de Croizat). Sin embargo, en el trabajo no se muestra y señalan que se presenta en un trabajo de Miller y Smith que en ese momento se encontraba en prensa). Lo anterior parece darle una identidad biogeográfica a la región, con base en la distribución de estos elementos ictiofaunísticos.

Miller y Smith (1986) fueron quienes al parecer establecieron una metodología derivada del análisis de trazos para explicar el origen y la geografía de los peces del centro de México. Para explicar la evolución de la ictiofauna de la Mesa Central, los autores reseñan un análisis de trazos de acuerdo con el método de Croizat (que citan, pero que en ningún momento ilustran) y sugieren la existencia de 3 trazos biogeográficos: 1) trazo de la Costa del Pacífico; 2) trazo del este a través de la Sierra Madre Occidental, y 3) trazo del Altiplano. Al parecer, este último indica una conexión entre la Mesa Central y la cuenca del río Bravo, evidenciada no sólo por la presencia de Menidia y Chirostoma sino también por algunas formas que presentan afinidades evolutivas con grupos actualmente restringidos principalmente al este de los Estados Unidos, en particular 2 especies del género Ictalurus (I. dugesii y un representante extinto), 3 catostómidos (Moxostoma mascotae, Moxostoma austrinum y uno extinto) y una especie extinta de lobina (Micropterus relictus).

\section{La Mesa Central en el contexto de los esquemas de regionalización de México}

Con el objeto de revisar críticamente el concepto de Mesa Central y los límites que han sido establecidos paraésta y contar con elementos para discutir la conveniencia o no de reconocerla como una región o provincia biogeografica, a continuación presentamos una comparación de esta región con diferentes regionalizaciones de nuestro país que están basadas en distintos criterios, para así poder definir si la circunscripción de la Mesa Central tiene relación con alguna de las áreas que han sido reconocidas en cada uno de esos esquemas. Para ello, hicimos uso de las bases de datos que están disponibles en la página web de la Comisión Nacional para el Conocimiento y Uso de la Biodiversidad (CONABIO, http://conabioweb.conabio. gob.mx /metacarto/metadatos.pl) y sobrepusimos, en cada uno de esos mapas, los límites de la Mesa Central de acuerdo con West (1964a, b). Como elemento adicional, dentro de cada uno se presenta la distribución de los principales elementos ictiofaunísticos que existen en la zona y que fundamentan las bases del reconocimiento de la Mesa Central como una región geográfica con límites bien establecidos. La distribución está basada en trabajos como los de Mateos et al. (2002) para Poeciliopsis infans, Barbour y Miller (1978), Coburn y Cavender (1992), Schönhuth y Doadrio (2003) para ciprínidos, particularmente de los géneros Notropis y Algansea, Domínguez-Domínguez et al. (2009) para diferentes grupos de godeidos y Miller et al. (2005) para otros grupos de peces como aterinópsidos e ictalúridos. Cabe señalar además que la Mesa Central ha sido reconocida como una zona de transición (Pérez-Ponce de León, 2003) donde convergen elementos de distinto origen biogeográfico. Por ello es importante mostrar en los mapas que se presentan a continuación, el carácter neártico o neotropical de los principales elementos que componen la fauna ictiológica de la zona. Asimismo, se resaltan también los grupos endémicos (como los goodeidos y aterinópsidos) que forman un componente fundamental en la región y que son de suma importancia en la explicación de los patrones y procesos que determinaron la historia biogeográfica de la misma.

\section{Mesa Central y regiones fisiográficas de México}

Dado que la caracterización de la Mesa Central establecida por West (1964a, b) fue fisiográfica, en primer término comparamos ésta con las regiones fisiográficas de México propuestas por Cervantes-Zamora et al. (1990a). Se observa claramente que, aunque ambas toman en cuenta los principales rasgos fisiográficos del país no existe congruencia alguna entre éstas (Fig. 6).

Recientemente, Nieto-Samaniego et al. (2005) realizaron un estudio con el fin de caracterizar la Mesa Central de México desde un punto de vista fisiográfico, dado que esta región ya había sido reconocida como una provincia fisiográfica (Raisz, in Nieto-Samaniego et al., 2005) siendo definida como "una cuenca rodeada por montañas más elevadas". Los autores señalan que en la observación de la configuración orográfica de la República Mexicana es evidente la existencia de dicha provincia, localizada hacia la región central del país, pero que el conocimiento que actualmente se ha alcanzado de la orografía y geología de esa región, así como la posibilidad de observar la república en su conjunto en imágenes de satélite y en modelos digitales de elevación, hacían necesaria una redefinición de sus límites como provincia fisiográfica.

Asimismo, Nieto-Samaniego et al. (2005) realizaron una descripción muy detallada de diferentes aspectos geológicos de la región y presentaron el mapa de la figura 7; sin embargo, no consideraron la propuesta original de West, publicada en 1964a. Se observa que la 


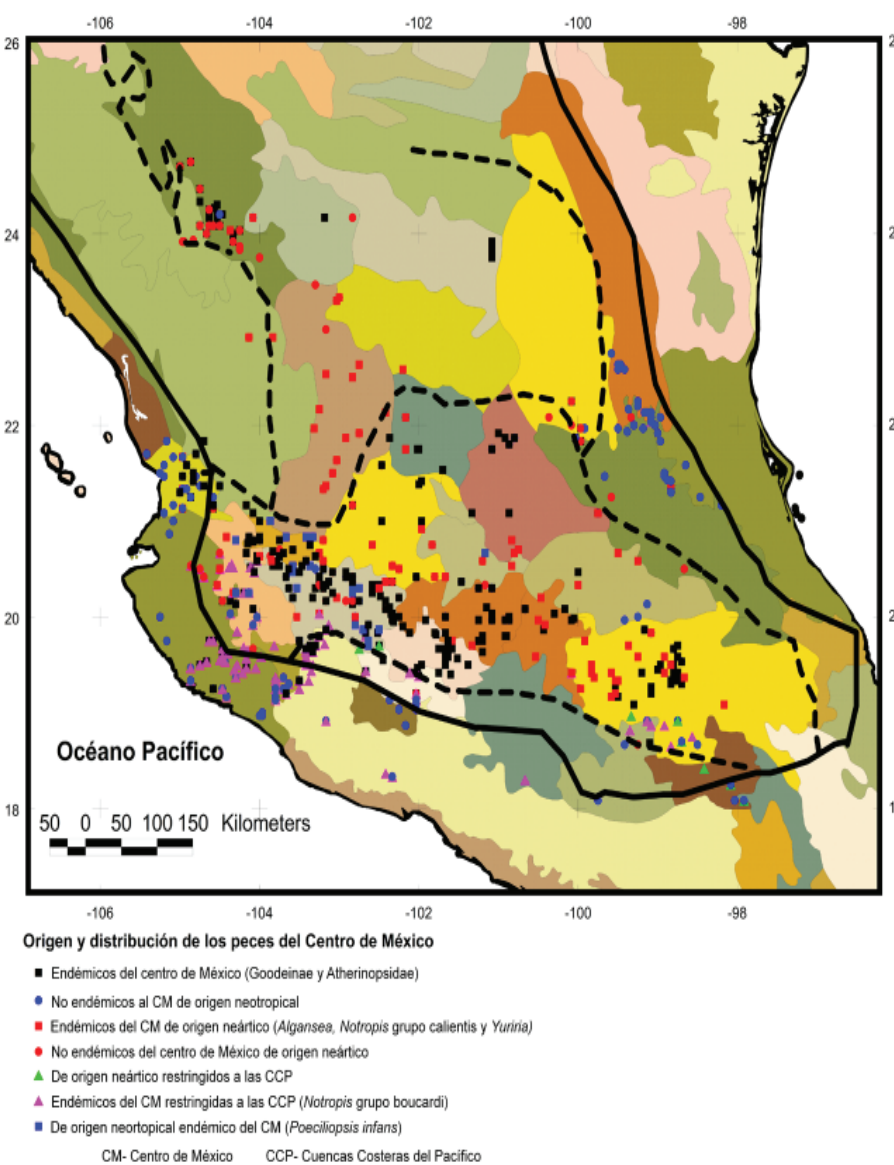

Figura 6. Regiones fisiogáficas de México. En líneas punteadas se representa la Mesa Central de México (West, 1964a). El fondo (en colores) representan las regiones fisiográficas de México propuestas por Cervantes-Zamora et al., (1990a). Las figuras sobrepuestas representan, por el color: En azul están representadas las especies de peces de origen neotropical, en rojo las neárticas y en negro las endémicas. Los círculos azules representan la distribución de Poeciliopsis infans. Los círculos rojos al clado calientis del género Notropis y al género Algansea. Los triángulos verdes al clado boucardi del género Notropis, restringido a la cuenca del Balsas y los triángulos rosas representan la tribu Ilyodontini (Goodeidae), restringida a las cuencas costeras del Pacífico.

circunscripción de la Mesa Central de West (1964a) es diferente a la propuesta por Nieto-Samaniego et al. (2005; Fig. 7); sin embargo, el concepto que tradicionalmente fue utilizado por los ictiólogos para explicar el origen y la evolución de la fauna fue el primero.

\section{Mesa Central y regiones morfotectónicas de México}

Posteriormente, se consideró el mapa de regiones morfotectónicas de México (Ferrusquía-Villafranca, 1990), el cual presenta las provincias y subprovincias de la República Mexicana con base en criterios morfotectónicos

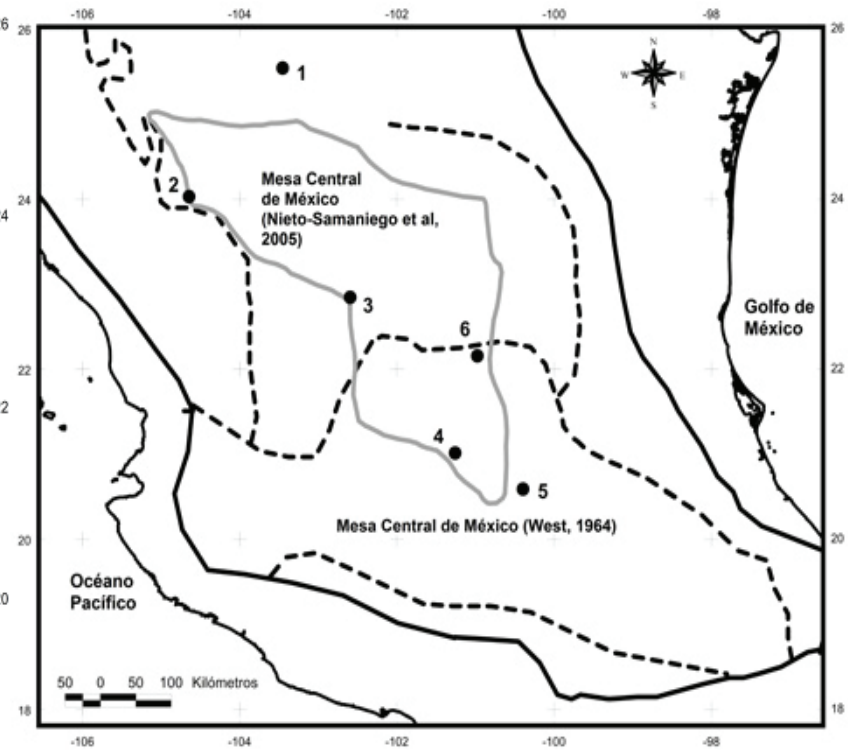

Figura 7. La Mesa Central como provincia fisiográfica de acuerdo con Nieto-Samaniego et al., (2005). En gris se circunscribe el concepto de estos autores y las líneas punteadas corresponden a la Mesa Central de México de acuerdo con West (1964a).

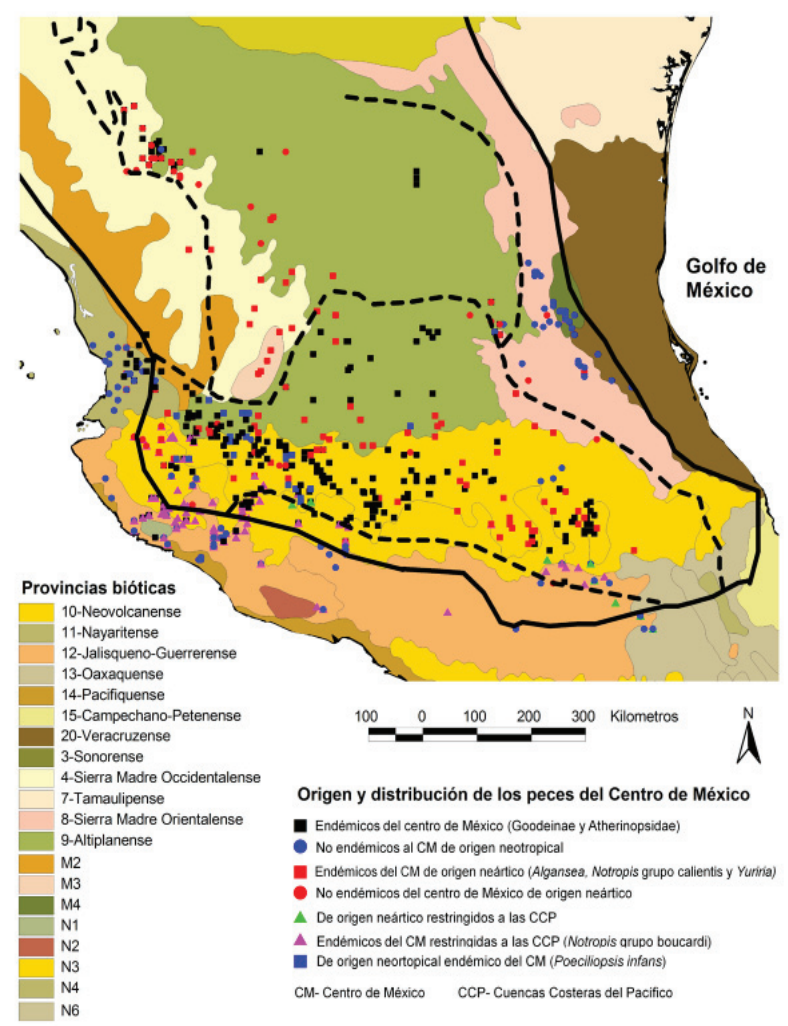

Figura 8. Regiones morfotectónicas de México. El fondo (en colores) representa las regiones bióticas de México (FerrusquíaVillafranca, 1990). Las líneas punteadas corresponden a la Mesa Central de México (West, 1964a). La referencia a la forma y color de las figuras sobrepuestas se encuentra en la misma figura 7. 
(Fig. 8). Es notorio que la Mesa Central comprende al menos 7 de las provincias reconocidas por este autor y que por lo mismo tampoco coincide con dicha regionalización.

Mesa Central y regiones hidrológicas de México

Tomando como criterio que el mayor numero de trabajos donde se cita la Mesa Central tal y como la describió West (1964a) están relacionados con la fauna acuática, se intentó circunscribir los límites de ésta con las regiones hidrológicas de México propuestas por Maderey y Torres-Ruata (1990; Fig. 9).

Se puede observar que al menos 7 cuencas hidrológicas diferentes se incluyen dentro de los límites de la Mesa Central, por lo que ésta tampoco se circunscribe a las regiones hidrológicas de México propuestas (Fig. 9). Con respecto a la distribución de la fauna, llama la atención que la región hidrológica del balsas representa un límite de distribución para las especies de origen neártico que se distribuyen dentro de la Mesa Central (color rojo en la figura 9).

\section{Mesa Central y curvas de nivel (altitud)}

Se consideraron también las curvas de nivel de acuerdo con los mapas de CONABIO (1998), con el fin de establecer una correlación entre los límites de la Mesa Central y la altitud (Fig. 10). Este mapa muestra que la Mesa Central de México parece acotarse más a las curvas de nivel de los 1400-2000 para su porción sur y este. También se consideraron las provincias biogeográficas establecidas a través del mapa de regiones bióticas de la CONABIO (1997) que establece 19 provincias biogeográficas, obtenidas a partir de 4 sistemas de clasificación, 3 biogeográficos (plantas vasculares, anfibios y reptiles y mamíferos) y 1 que incluye los principales rasgos morfotectónicos de México.

En el mapa de la figura 11 se puede observar que la Mesa Central incluye al menos 6 regiones biogeográficas, y a pesar de que comprende casi en su totalidad aquella que corresponde con el eje Neovolcánico (= Cinturón Volcánico Transmexicano), no se circunscribe únicamente a ésta, por lo cual tampoco existe una coincidencia con este esquema de regionalización.

En los últimos años, diferentes autores han intentado establecer un esquema de regionalización biótica de México a partir del reconocimiento de componentes bióticos, utilizando distintas metodologías derivadas de la biogeografía histórica, como el método panbiogeográfico (trazos) y el análisis de parsimonia de endemismos (PAE, por sus siglas en inglés), y poniendo a prueba las relaciones entre los componentes, mediante el empleo de métodos de biogeografía cladística, como el análisis de parasimonia de Brooks (BPA, por sus siglas en inglés) o el análisis de componentes. Estos análisis hacen uso de los patrones de distribución de las especies como elemento para establecer una regionalización biogeográfica a manera de sistema jerárquico que sea útil para categorizar las áreas en términos de su biota. A continuación se mencionan 3 de los trabajos que consideramos más importantes, con los cuales también se presentan los límites de la Mesa Central, para determinar si esta región está circunscrita a alguna de las regiones de endemismo que se describen en esos trabajos.

Marshall y Liebherr (2000) realizaron un análisis de biogeografía cladística de la Zona de Transición Mexicana, proponiendo una regionalización de áreas de endemismo que se definen a partir del sobrelapamiento del intervalo de distribución de 33 taxa de insectos, vertebrados (incluyendo algunos de peces dulceacuícolas) y angiospermas (Fig. 12).

Claramente se observa que la Mesa Central contiene casi en su totalidad al área referida como TRAN (Sierra Transvolcánica), pero que su límite al noroeste está sobrepuesto con otra zona de endemismo (OCC) que, de acuerdo con Marshall y Liebherr (2000) comprende una gran extensión del centro de México que incluye la Sierra Madre Occidental y el Altiplano Central. El límite sureño de la Mesa Central sí parece coincidir al menos con el límite del TRAN, representado por la depresión del Balsas. Halas et al., (2005) utilizaron los datos de Marshall y Liebherr (2000) para realizar un análisis de BPA secundario con el objeto de probar la hipótesis de diversificación biótica a partir de "pulsos de los taxones" como resultado de episodios alternados de vicarianza y expansión biótica. En ese mismo año, Brooks (2005) utilizó el método de análisis filogenético para comparar árboles (PACT, por sus siglas en inglés) para dar mayor soporte a la hipótesis de "pulsos de taxones" en virtud de que el análisis de BPA no es adecuado para explicarla. En estos trabajos, identifican la separación entre la región Sierra Transvolcánica (TRAN) y la Sierra Madre del Sur (SUR) como una zona de vicarianza. En esa forma, los trabajos a que nos referimos aportaron algunas ideas para explicar los patrones de distribución de las especies en las denominadas áreas de endemismo propuestas por Marshall y Liebherr (2000), más no se utilizaron como tal para cuestionar o modificar las regiones que fueron definidas desde un principio.

Un conjunto de trabajos (Morrone et al., 1999, 2002; Morrone y Márquez, 2001, 2003) han utilizado el método panbiogeográfico y el análisis de parsimonia de endemismos para establecer las provincias biogeográficas mexicanas, basados en diferentes taxa. Estos trabajos sentaron las bases para que recientemente Morrone (2005) presentara el trabajo de síntesis más completo que se ha realizado hasta ahora, con una propuesta de 


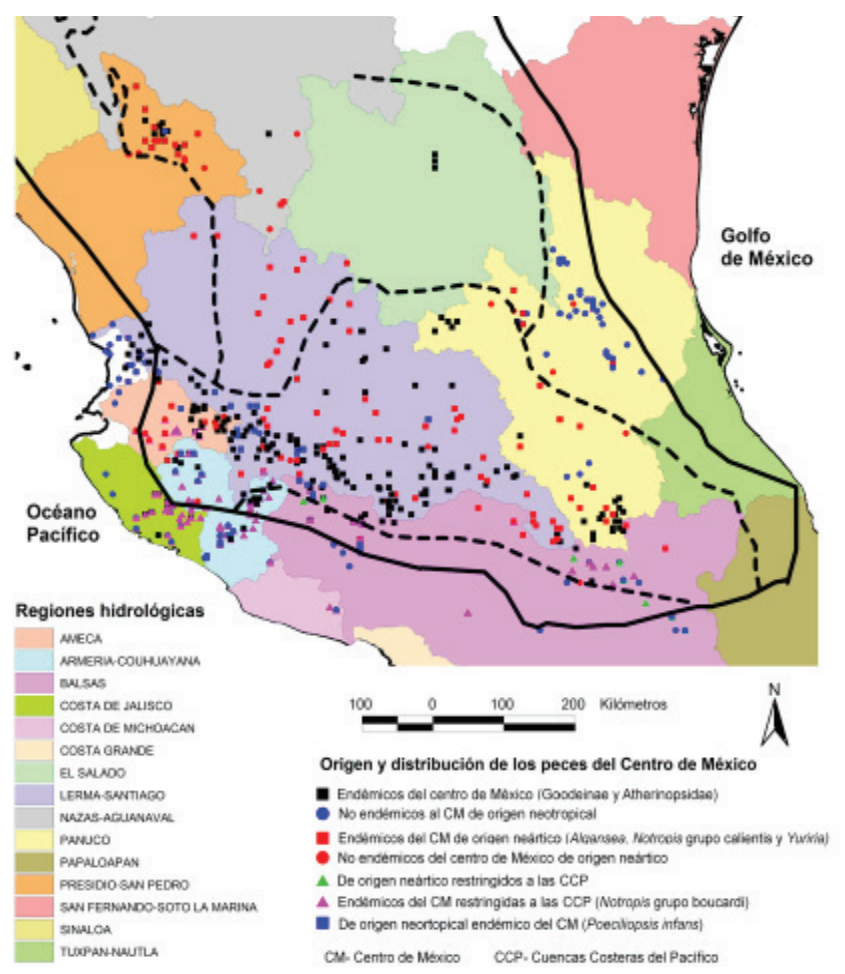

Figura 9. Regiones hidrológicas de México. El fondo (en colores) representa regiones hidrológicas (Maderey y TorresRuata, 1990). La línea punteada representa los límites de la Mesa Central de México de acuerdo con West (1964a). La referencia a la forma y color de las figuras sobrepuestas se encuentra en la propia figura 9.

regionalización biogeográfica de México. Morrone (2005) basó su propuesta en la idea de que el reconocimiento de componentes bióticos constituye una primera etapa hacia una teoría biogeográfica sintética, y propuso que en México se podían caracterizar 3 componentes bióticos principales, cada uno conteniendo elementos bióticos característicos, o una combinación de éstos: 1) el componente neártico que incluye las áreas áridas subtropicales del norte del país (provincias de California, Baja California, Sonora, Altiplano Mexicano y Tamaulipas). El componente transicional o Zona de Transición Mexicana que incluye las áreas básicamente montañosas del centro del país (las provincias Sierra Madre Oriental, Sierra Madre Occidental, Eje Volcánico Transmexicano, Cuenca del Balsas y Sierra Madre del Sur), y 3) el componente neotropical que incluye

Figura 11. Provincias biogeográficas de México. El fondo (en colores) se representa las provincias biogeográficas (CONABIO, 1997). La línea punteada delimita la Mesa Central de México según West (1964a). La referencia a la forma y color de las figuras sobrepuestas se encuentra en la misma figura 11.

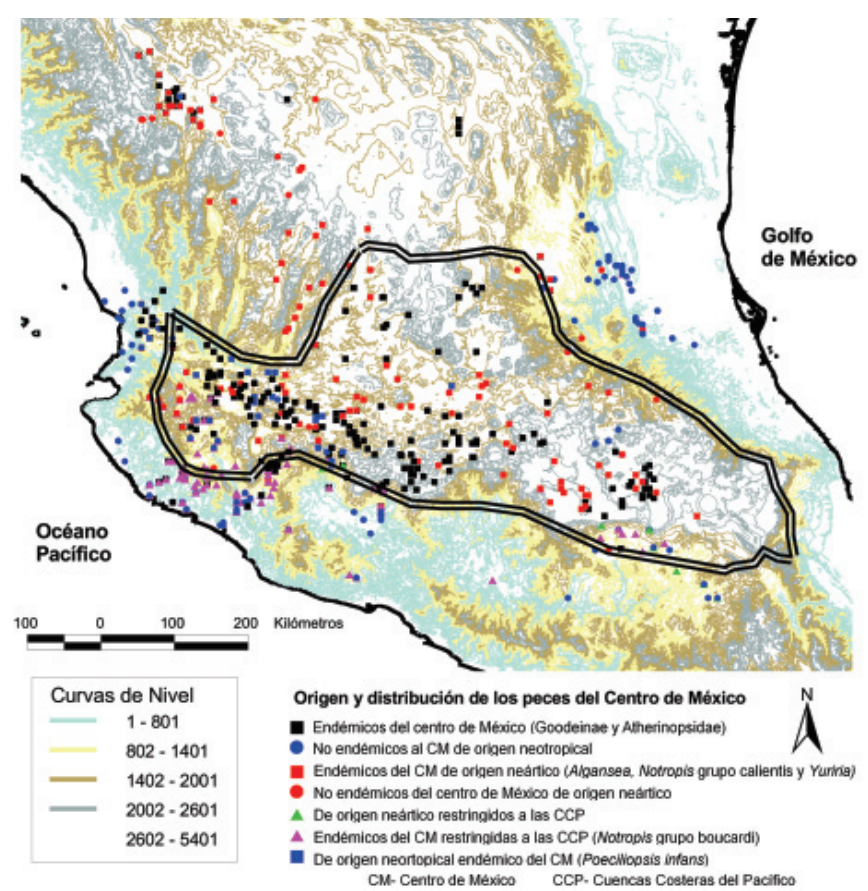

Figura 10. Curvas de nivel del territorio Mexicano. El fondo (en colores) los distintos niveles (CONABIO, 1998). Las líneas punteadas representan la Mesa Central de México. La referencia a la forma y color de las figuras sobrepuestas se encuentra en la propia figura 10.

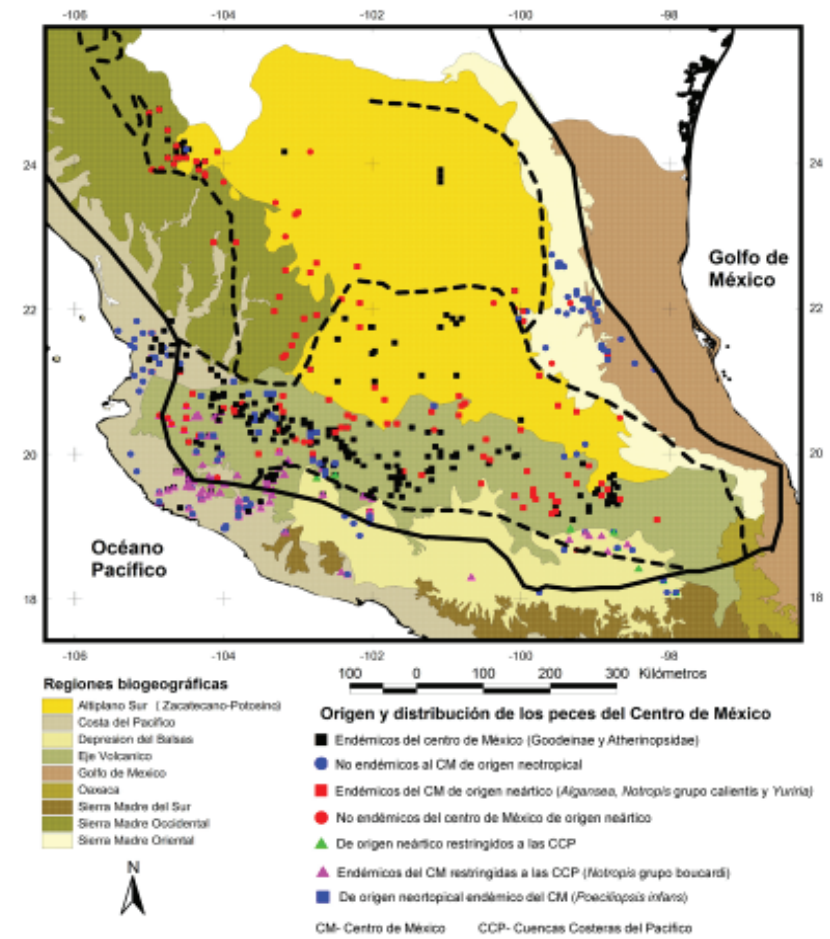




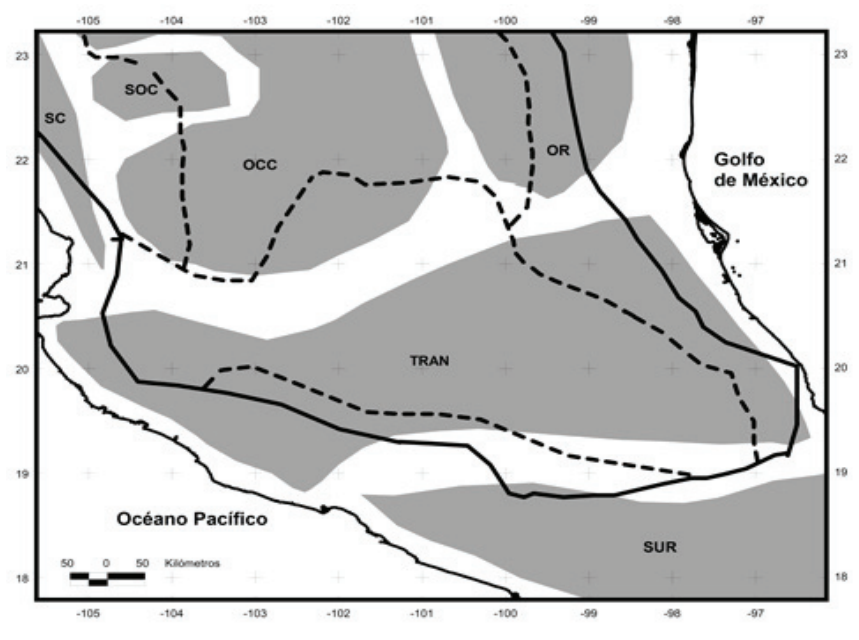

Figura 12. Areas de endemismo de México, AZ, Arizona; CGH, Tierras altas de Chiapas y Guatemala; OCC, Sierra Madre Occidental-Altiplano Central; ORI, Sierra Madre Oriental; SD, Desierto de Sonora; SOC, Sur de la Sierra Madre Occidental; SUR, Sierra Madre del Sur; TAL, Cordillera de Talamancan; TRAN, Sierra Transvolcánica. En línea punteada se presentan los límites de la Mesa Central (Modificado de Marshall y Liebherr, 2000).

áreas tropicales húmedas y subhúmedas del sur de México (las provincias Costa Pacífica Mexicana, Golfo de México, Chiapas y Península de Yucatán). En este mismo trabajo se reconoce que el componente transicional incluye la combinación de elementos paleoamericanos, neárticos, mesoamericanos tropicales y mesoamericanos de montaña y además, que los eventos vicariantes asociados con la evolución biótica de éste están íntimamente ligadas al vulcanismo asociado al surgimiento del Eje Volcánico Transmexicano. La conformación de la Mesa Central estuvo precisamente determinada por esos mismos factores, sin embargo, Morrone (2005) consideró que esta provincia ictiofaunística era equiparable a la provincia del Eje Volcánico Transmexicano (EVT).

La figura 13 muestra que tampoco se circunscriben los límites de acuerdo con la definición de Mesa Central que propusiera West (1964a) y que utilizaran los ictiólogos para denotar una provincia que, desde el punto de vista de la distribución de los peces dulceacuícolas le da una identidad como área de endemismo, con elementos que exhiben la naturaleza de ésta como zona de transición. Asimismo, como en otros esquemas de regionalización, la Mesa Central incluye la provincia del Cinturón Volcánico Transmexicano, sin embargo, dentro de sus límites también quedan comprendidas algunas porciones de las provincias del Altiplano Mexicano, Balsas, Sierra Madre Occidental

\section{y Sierra Madre Oriental. \\ Consideraciones finales}

El análisis antes presentado muestra claramente que la Mesa Central de México no puede considerarse una provincia biogeográfica. En primer lugar, sus límites fueron establecidos con base en características fisiográficas que al parecer la distinguen de otras partes del territorio nacional, y si bien, en principio esta delimitación se correspondió casi de manera natural con la distribución de los principales elementos de la fauna ictiológica dulceacuícola (aterinópsidos, goodeidos y ciprínidos), no existe correspondencia alguna ni con los esquemas de regionalización que toman en cuenta aspectos geomorfológicos, hidrogeográficos, o altitudinarios, ni con los esquemas que se basan en la composición biótica con base en distintos taxa. Tampoco puede considerarse que la Mesa Central sea una región "sinónima" de la provincia del Eje Volcánico Transmexicano como fue sugerido por Morrone (2005), pues una parte importante de la Mesa, sobretodo en su porción norteña, no queda dentro de los límites impuestos para el EVT.

Otro factor que determina la confusión en el manejo del término es la delimitación diferencial que tiene en los estudios geológicos (Moran, 1984; Nieto-Samaniego et al., 2006), y entre éstos y aquellos basados en aspectos fisiográficos (West 1964a). Los estudios ictiofaunísticos (Barbour, 1973, Miller et al., 2005) basan sus análisis de distribución en la descripción de West (1964a). La propuesta de Nieto-Samaniego et al. (2006) de la circunscripción de la Mesa Central no concuerda con las propuestas que han tomado en cuenta tan solo el aspecto geológico (Morán, 1984) o geomorfológico (FerrusquíaVillafranca, 1990) y mucho menos concuerda con la propuesta de West (1964a).

Todo lo anterior apunta a que el concepto de Mesa Central ha tenido una utilidad práctica para algunos sectores de la comunidad científica, particularmente los ictiólogos y parasitólogos quienes encuentran una cierta correspondencia en la distribución de los elementos bióticos que habitan en esta zona. Sin embargo, el concepto no puede sostenerse dada su no correspondencia con ningún esquema de regionalización del territorio nacional, principalmente aquellos que hacen uso de los componentes bióticos.

Recientemente, Escalante (2009) describió en detalle los principales conceptos y métodos asociados con el descubrimiento de los patrones biogeográficos usados en la construcción de regionalizaciones biogeográficas naturales, es decir, la categorización de las áreas geográficas en términos de su biota, siendo la provincia la unidad básica. Un área natural es aquella que, cuando se 
expresa como una entidad en un mapa, es homogénea en alguna característica y su identificación sobre un mapa es relativamente sencilla (Miller, 1994a in Escalante, 2009). De esta manera, como unidades naturales se consideran, por ejemplo, aquellas áreas limitadas por una cota altitudinal, un polígono con la presencia de un tipo único de hábitat, vegetación o ecosistema, etc., pero en el contexto de la biogeografía histórica, la naturalidad de un área tiene que ver más con la identificación de un origen biótico común u homología biogeográfica (Morrone, 2005). Tomando en cuenta lo anterior, si bien la Mesa Central de México puede considerarse una unidad fisiográfica, no es congruente con el planteamiento de construir una regionalización de la biota mexicana que se basa en la búsqueda de la homología biogeográfica, y por ello es claro que dicha área no se circunscribe como una provincia biogeográfica.

Recientemente, los autores de este trabajo analizaron los patrones de biogeografía histórica de los goodeidos, uno de los grupos de peces dulceacuícolas más representativos de la zona geográfica cuyos límites hemos puesto a prueba en la presente contribución. Para ello se emplearon métodos cladísticos para construir un cladograma general de áreas y se presentó una regionalización de las áreas de distribución actual de los goodeidos en distintas cuencas hidrológicas del centro de México, dentro de la Mesa Central, para intentar explicar los procesos que determinaron la diversificación de estos peces, misma que está claramente asociada a una historia geológica compleja, con una intensa actividad tectónica y volcánica (Domínguez-Domínguez et al., 2006a, 2006b). Con el propósito de intentar circunscribir los límites de distribución de los goodeidos dentro de la Mesa Central de acuerdo con la propuesta de West (1964a), igualmente se superpuso dicho esquema sobre las 23 regiones que fueron identificadas en dichos estudios (Fig. 14), aunque cabe señalar que en el primero de éstos (Domínguez-Domínguez et al., 2006 a), sólo consideró 18 regiones.

En la figura 14 se observa que la Mesa Central incluye en su totalidad las cuencas del Valle de México, Lerma Alto, Medio y Bajo, Chapala, Cuitzeo, Pátzcuaro, Zirahuén, Zacapú y Cotija, y también se incluyen las partes altas de las cuencas de los ríos Pánuco, Balsas, Coahuayana, Armería, Ameca y Verde (tributario del río Santiago); sin embargo, excluye por completo las cuencas de los ríos Nazas-Aguanaval, Compostela, Purificación-Mascota, Ayuquíla y Mezquital, mismas que forman parte del área de distribución natural de los goodeidos.

Si bien los peces de la familia Goodeidae se distribuyen principalmente en cuencas hidrológicas comprendidas dentro la Mesa Central, no todos sus integrantes quedan incluidos, por lo cual la distribución de los peces no refleja necesariamente los límites establecidos con base en criterios fisiográficos, como lo interpretaron autores como Barbour (1973), Echelle y Echelle (1984), Miller y Smith (1986), y más recientemente Minckley et al. (2005). A partir de estas consideraciones, sugerimos entonces no utilizar la Mesa Central como una región geográfica cuando se intente circunscribir la flora y fauna que en esa zona existe para describir patrones biogeográficos. Deberá referirse entonces a la cuenca hidrológica en particular, o bien, si se trata de amplias distribuciones, referirse al centro de México. Todo esto ante el hecho innegable de que los esquemas con los que se cuenta en la actualidad no hacen uso de los elementos faunísticos y florísticos dulceacuícolas.

Una de las causas por las cuales la Mesa Central no constituye una provincia biogeográfica se debe a que desde el punto de vista faunístico sus límites están establecidos en relación con la fauna acuática. Las cuencas hidrológicas de los principales ríos del centro de México se caracterizan por originarse en zonas montañosas elevadas y descargar sus aguas, ya sea hacia la costa del Pacífico mexicano, o bien, hacia el golfo de México, a través de zonas bajas, captando descargas de numerosos afluentes a lo largo de su recorrido, lo que hace que la cuenca hidrológica como tal pueda contener elementos bióticos ampliamente distribuidos en altitudes diferenciales. Algunos goodeidos habitan en zonas altas de la cuenca del río Balsas en los estados de Puebla y Michoacán, por ejemplo, Illyodon whitei, y la misma especie se encuentra también en algunas partes bajas del río Balsas en los estados de Morelos, Michoacán y Guerrero. A su vez, la cuenca hidrológica podría subdividirse en virtud de aquellos componentes que se encuentran en determinados puntos. En el caso del río Balsas, por ejemplo, existen especies de peces (cíclidos y carácidos) que sólo se encuentran en las partes bajas de la cuenca hidrológica, mientras que algunas otras (ciprínidos y otros godeidos), sólo en las partes altas (Miller et al., 2005).

La mayoría de los esquemas de regionalización que han sido propuestos hasta el momento se basan fundamentalmente en elementos bióticos terrestres, y muy pocos toman en cuenta los organismos acuáticos. Para estos últimos, la tierra constituye una barrera biogeográfica que determina primordialmente la historia de su diversificación dada su incapacidad para sobrepasar dichas barreras. A diferencia de esto, muchas especies terrestres, dependiendo de su forma de locomoción, pueden tener capacidad de dispersión incluso a través de barreras impuestas por el surgimiento de cuerpos de agua. Por ello, si los esquemas de regionalización biogeográfica toman en cuenta exclusivamente la biota terrestre, o sólo incluyen algunos representantes acuáticos, no se generarán patrones generales. La pregunta es si, entonces, debe existir una 


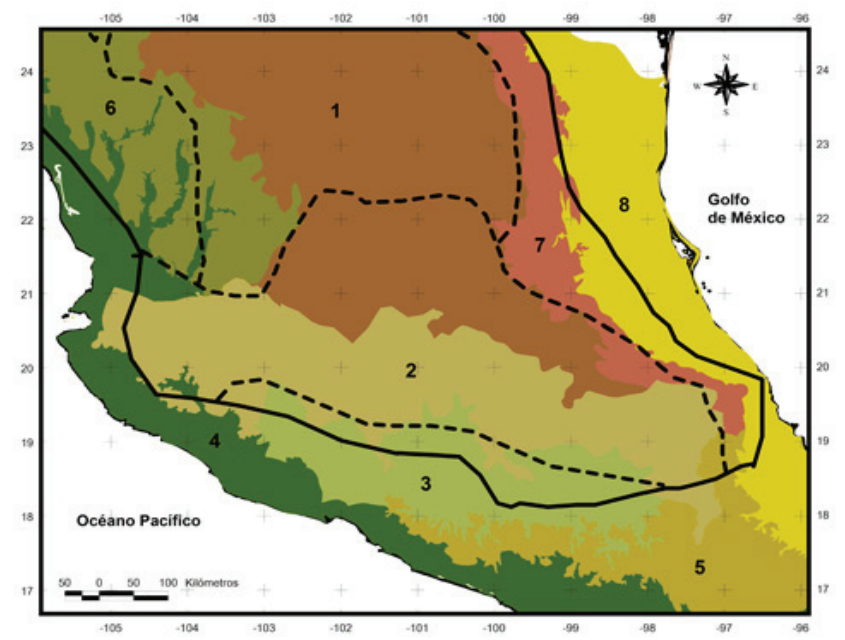

Figura 13. Regionalizacion biogeográfica de México de acuerdo con Morrone (2005, p. 230). En color se incluyen las provincias del centro de México: 1. Altiplano Mexicano, 2. Eje Volcánico Transmexicano, 3. Cuenca del Balsas, 6. Sierra Madre Occidental y 7. Sierra Madre Oriental. Las líneas punteadas denotan la Mesa Central de México de acuerdo con West (1964a).

regionalización biogeográfica para especies terrestres y otra para especies acuáticas o si, por el contrario, debiera buscarse una regionalización que incluyera todos los componentes bióticos, con los problemas inherentes de distribución que pueden existir para los organismos acuáticos anteriormente descritos.

Como ejemplo utilizaremos la provincia biogeográfica delEVT de Morrone (2005). Esta región se ubica en el centro de México, en los estados de Guanajuato, Distrito Federal, Estado de México, Jalisco, Michoacán, Puebla, Oaxaca, Tlaxcala y Veracruz e incluye las elevaciones mayores del territorio mexicano. Corresponde básicamente al sistema montañoso del Eje Volcánico Transmexicano, situado aproximadamente a lo largo de los paralelos $19^{\circ}$ y $20^{\circ}$ de latitud norte, que constituye el límite austral del Altiplano Mexicano y lo separa de la Cuenca del Balsas. La flora y fauna que define a ésta como una zona de endemismo y por ende como una provincia (Morrone, 2005, p. 236-237) incluye únicamente elementos terrestres, con la excepción de 2 especies de anfibios (Ambystoma rivulare y Rana montezumae).

El río Lerma, que constituye el principal componente fisiográfico del centro de México, se origina en zonas elevadas en el estado de México, y su cauce y afluentes principales atraviesan en sentido este-oeste los estados de Guanajuato, Michoacán y Jalisco para desembocar en el lago de Chapala, y de ahí, a través del río Santiago, hacia la costa del Pacífico Mexicano. Este río representa además

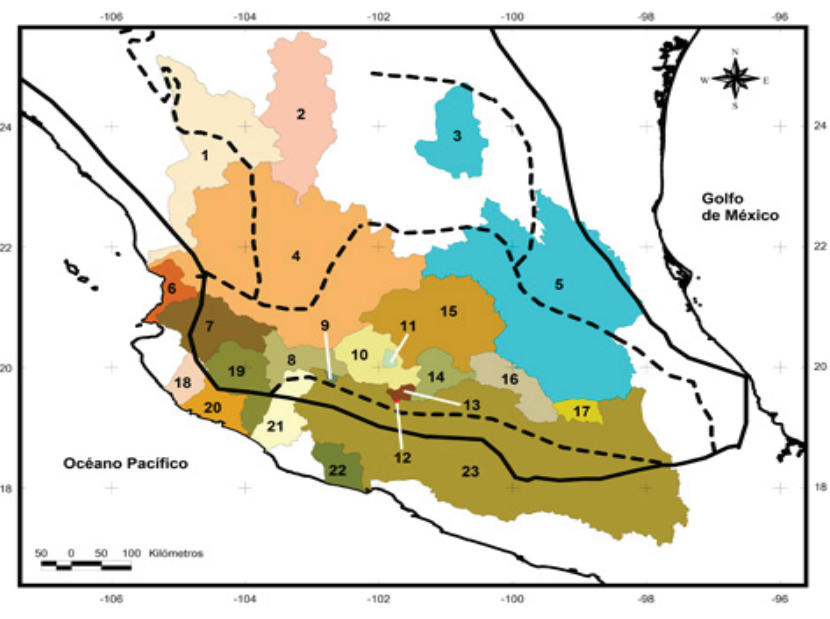

Figura 14. A) Areas que fueron establecidas sobre la distribución de los goodeidos en el centro de México: 1. Mezquital, 2. NazasAguanaval, 3. Moctezuma-Venados, 4. Santiago, 5. Panuco, 6. Compostela, 7. Ameca, 8. Chapala, 9. Cotija, 10. Bajo Lerma, 11. Zacapu, 12. Zirahuen, 13. Patzcuaro, 14. Cuitzeo, 15. Medio Lerma, 16. Alto Lerma, 17. Valle de México, 18. Purificación, 19. Armería-Ayuquila, 20. Marabasco, 21. CoahuayanaTamazula, 22. Coalcoman, 23. Balsas. B) Regionalización biogeográfica realizada de acuerdo a la distribución de los peces de la subfamilia Goodeinae. Las líneas punteadas representa los límites de la Mesa Central de acuerdo con West (1964a).

la principal zona de diversificación de la fauna ictiológica del centro de México, cuyas relaciones se establecen claramente con cuencas hidrológicas aledañas, como las de los ríos Balsas, Pánuco, Mezquital, Ameca, Armería y Coahuayana, con quienes tuvo repetidos eventos de captura-recaptura por actividad tectónica y volcánica (Domínguez-Domínguez et al., 2006a).

La presencia de especies de amplia distribución en estas cuencas generaría resultados ambiguos si fueran incluidos en algún análisis biogeográfico, dado que dichas especies estarían presentes en más de una región de endemismo. No pretendemos señalar que las ambigüedades determinan que los análisis biogeográficos carezcan de valor, más bien señalamos la importancia que tiene la inclusión de todos los elementos bióticos en la generación de un esquema de regionalización biogeográfica.

Al analizar los patrones de distribución de taxa dulceacuícolas en la Zona de Transición Mexicana, Huidobro et al. (2006) utilizaron datos de 22 especies del género Poeciliopsis, 34 de 4 géneros de cangrejos pseudotelfusinos y 22 de 9 géneros de angiospermas y realizaron un análisis panbiogeográfico y un análisis de parsimonia de endemismos para encontrar que los patrones de distribución de esta muestra de organismos acuáticos a través de 3 trazos generalizados a los que 
llamaron: Pacífico del Norte Mexicano, Pacífico del Centro Mexicano y Sur de Mexico-Guatemala, corresponden con trazos generalizados de otros elementos bióticos, como el llamado Mesoamericano de Montaña, que caracterizan entre los 2000 y $3000 \mathrm{~m}$ de altitud.

Los autores de esta contribución hemos concluido que la coincidencia de los patrones que encuentran entre los elementos bióticos acuáticos con aquellos obtenidos para elementos terrestres parecería indicar que los mismos procesos geobióticos son los que determinaron dichos patrones. En nuestra opinión, esta conclusión es prematura y requiere ser corroborada al integrar un mayor número de elementos bióticos acuáticos en el análisis. La falta de resolución en el cladograma derivado del análisis de parsimonia de endemismos, en relación, por ejemplo, con la posición basal y no resuelta de la cuenca del Río Lerma, o su nula relación con la cuenca del río Santiago, con quien comparte no sólo un continuo en la corriente hidrológica sino también numerosos elementos ictiofaunísticos, claramente indica falta de información de una de las zonas más importantes del país desde el punto de vista hidrográfico, donde una intensa dinámica geotectónica y paleoclimática ha configurado la superficie de esa parte del territorio, y ha causado además repetidos eventos de fragmentación que resultaron en eventos de vicarianza y que, en su mayoría, determinaron la historia evolutiva de los componentes acuáticos (Domínguez-Domínguez et al., en prensa). Por ello, sugerimos que si la flora y fauna terrestres y acuáticas están sujetas a los mismos procesos geobióticos, se requiere elaborar un esquema de regionalización biogeográfica que integre en su totalidad elementos bióticos acuáticos, para así poder encontrar los componentes bióticos que sustenten esta regionalización. Esto es de gran importancia pues como sugiere Morrone (2009) la identificación de los componentes bióticos, que son las unidades biogeográficas básicas, es el primer paso para cualquier análisis de biogeografía evolutiva. Por el contrario, si se demostrara que los procesos geobióticos que determinan la distribución de elementos acuáticos y terrestres no son comunes, entonces se podría explorar la posibilidad de contar con esquemas de regionalización para cada uno de esos elementos bióticos.

\section{Agradecimientos}

Los autores de esta contribución deseamos agradecer a Rodolfo Pérez, Rogelio Rosas y Hugo Mejía, por las continuas discusiones que tuvimos sobre el tema que presentamos. Este trabajo fue financiado parcialmente con recursos de los proyectos del Programa de Apoyo a Proyectos de Investigación e Innovación Tecnológica
(PAPIIT-UNAM Núm. IN209608) y por el Consejo Nacional de Ciencia y Tecnología (CONACyT Núm. 83043). Parte del trabajo fue escrito durante el año sabático de G.P.P L. en el Departamento de Nematología de la Universidad de California-Davis; por lo cual agradecemos al Dr. Steve Nadler el apoyo y las facilidades prestadas, $\mathrm{y}$ al programa UCMEXUS-CONACYT (University of California Institute for Mexico and the United StatesConsejo Nacional de Ciencia y Tecnología) por la beca otorgada.

\section{Literatura citada}

Barbour, C. D. 1973. A biogeographical history of Chirostoma (Pisces:Aterinidae): A species flock from the Mexican Plateau. Copeia 1973: 533-556.

Barbour, C. D. y R. R. Miller. 1978. A revision of the Mexican cyprinid fish genus Algansea. Miscellaneous. Publications. Museum of Zoology, University of Michigan 155:1-72.

Barbour, C. D. y R. R. Miller. 1994. Diversification in the Mexican cyprinid fish Algansea monticola (Pisces: Cyprinidae), with description of a new subspecies. Copeia 1994: 662-676.

Brooks, D. R. 2005. Historical biogeography in the age of complexity: expansion and integration. Revista Mexicana de Biodiversidad 76:79-94.

Cervantes-Zamora, Y., S. L. Cornejo-Olgín, R. Lucero-Márquez, J. M. Espinoza-Rodríguez, E. Miranda-Víquez y A. PinedaVelázquez. 1990a. Provincias Fisiográficas de México. Extraído de Clasificación de regiones naturales de México II, IV.10.2. Atlas nacional de México. Instituto de Geografía, UNAM/CONABIO, México, D.F. http://conabioweb. conabio.gob.mx/metacarto/info_completa.pl?id=19. Consulta: 021208.

Cervantes-Zamora, Y., S. L.Cornejo-Olguín, R. Lucero-Márquez, J. M. Espinosa-Rodríguez, E. Miranda-Víquez y A. PinedaVelázquez. 1990b. Clasificación de regiones naturales de México, IV. 10. 2. Atlas nacional de México. Instituto de Geografía, UNAM/CONABIO, México, D.F. http:// conabioweb.conabio.gob.mx/metacarto/info_completa. pl?id=387. Consulta: 021208 .

Coburn, M. M. y T. T. Cavender. 1992. Interrelationships of North American cyprinid fishes. In Systematics, historical ecology, and North American freshwater fishes. R.L. Mayden(ed.), Stanford University Press, California. p. 328-373.

CONABIO. 1997. Provincias biogeográficas de México. Comisión Nacional para el Conocimiento y Uso de la Biodiversidad, México, D.F.http://conabioweb.conabio.gob. mx/metacarto/metadatos.pl; 10 enero, 2007.

CONABIO. 1998. Topografía de México. Escala 1:250 000, Extraído del modelo digital del terreno. Instituto Nacional de Estadística, Geografía e Informática, México, D.F.

Corona, M. A., V.H. Toledo, y J. J. Morrone. 2007. Does the TransMexican Volcanic Belt represent a natural biogeographical unit? An analysis of the distributional patterns of Coleoptera. Journal of Biogeography 34:1008-1015.

De Buen, F. 1943. Los lagos michoacanos. I. Caracteres generales. 
El lago de Zirahuén. Revista de la Sociedad Mexicana de Historia Natural 4:211-232.

Domínguez-Domínguez, O., I. Doadrio, y G. Pérez-Ponce de León. 2006a. Historical biogeography of some river basins in Central Mexico evidenced by their goodeine freshwater fishes: A preliminary hypothesis using secondary Brooks Parsimony Analysis (BPA). Journal of Biogeography 33:1437-1447.

Domínguez-Domínguez, O., E. Martínez-Meyer, L. Zambrano, y G. Pérez-Ponce de León. 2006b. Using ecological-niche modeling to prioritize conservation areas in the Mesa Central of Mexico: a case study with livebearing freshwater fishes (Goodeidae). Conservation Biology 20:1730-1739.

Domínguez-Domínguez, O., C. Pedraza-Lara, N. GurrolaSánchez, R. Pérez-Rodríguez, I. Israde-Alcántara, V. Hugo Garduño-Monroy, I. Doadrio, G. Pérez-Ponce de León y D. R. Brooks (en prensa). Historical biogeography of the Goodeinae (Cyprinodontiforms). In Viviparous fishes II, M. C. Uribe-Aranzabal y H. Grier (eds.). New Life, Orlando, Florida.

Echelle, A. A., y A. F. Echelle. 1984. Evolutionary genetics of a "species flock" Atherinid fishes on the Mesa Central of Mexico. In The evolution of species flocks, A. A. Echelle e I. Kornfield (eds.). University of Maine at Orono. p. 111-127.

Escalante, T.2009. Un ensayo sobre regionalización biogeográfica. Revista Mexicana de Biodiversidad 80:551-560.

Ferrusquía-Villafranca, I. 1998. Geología de México: una sinopsis. Instituto de Biología-UNAM, México.

Ferrusquía-Villafranca, I. 1990. "Provincias Bióticas (con énfasis en criterios morfotectónicos)" en Regionalización Biogeográfica, IV.8.10. Atlas Nacional de México. Vol. II. Esacal 1. 4000000. Instituto de Geografía, UNAM. México. http://conabioweb.conabio.gob.mx/metacarto/info_ completa.pl?id=42. Consulta: 021208 .

Granados-Ramírez, R., T. Reyna-Trujillo, G. Gómez-Rodríguez, y J. Soria-Ruiz. 2004. Analysis of NOAA-AVHRR-NDVI images for crops monitoring. International journal of remote sensing 25:1615-1627.

Halas, D., D. Zamparo, y D. R. Brooks. 2005. A historical biogeographical protocol for studying biotic diversification by taxon pulses. Journal of Biogeography 32:249-260.

Maderey, R. L. y C. Torres-Ruata. 1990. Cuencas hidrológicas. en Hidrogeografía e hidrometría. IV.6.1.Atlas Nacional de México.Instituto de Geografía, UNAM, México. Instituto de Geografía, UNAM/CONABIO, México, D.F. http:// conabioweb.conabio.gob.mx/metacarto/info_completa. pl?id=37. Consulta: 021208 .

Maldonado-Koerdell, M. 1964. Geohistory and Paleogeography of Middle America. In: Handbook of Middle America Indians, Wanchope, R. y R. C. West (eds.). University of Texas Press, USA. p. 2-32.

Marshall, C. J., y J. K. Liebherr. 2000. Cladistic biogeography of the Mexican transition zone. Journal of Biogeography 27:203-216.

Mateos, M., O. I. Sanjur, y R. C. Vrijenhoek. 2002. Historical biogeography of the livebearing fish genus Poeciliopsis (Poeciliidae:Cyprinodontiformes). Evolution 56: 972-984.

Meek, S. E. 1904. The fresh-water fishes of Mexico North of the Isthmus of Tehuantepec. Fieldiana Columbian Museum Publications 93: 1-252.

Miller, R. R., W. L. Minckley, y S. M. Norris. 2005. Freshwater fishes of México. The University of Chicago Press, Chicago. $490 \mathrm{p}$.

Miller, R.R. y M. L. Smith. 1986. Origin and geography of the fishes of central Mexico. In: The zoogeography of North American freshwater fishes, Hocutt, C.H. y Wiley E.O. (eds.). Wiley-Interscience Publications, New York. p. 487519.

Minckley, W.L., R.R. Miller, C.D. Barbour, J.J. Schmitter-Soto, y S.M. Norris. 2005. Historical Ichthyogeography. In: Miller, R. R., W.L. Minckley, and S.M. Norris (eds.). Freshwater fishes of México. The University of Chicago Press, Chicago. p. 24-47.

Morán, Z. D. J. 1984. Geología de la Republica Mexicana. Instituto Nacional de Estadistica, Geografía e Informática, México. 87 p.

Morrone, J. J. 2004a. Homología biogeográfica: las coordenadas espaciales de la vida. Cuadernos del Instituto de Biología 37, Instituto de Biología, UNAM, México, D.F. 199 p.

Morrone, J. J. 2004b. Panbiogeografía, componentes bióticos y zonas de transición. Coleopterists Bulletin 48:149-162.

Morrone, J.J. 2005. Hacia una síntesis biogeográfica de México. Revista Mexicana de Biodiversidad 76:207-252.

Morrone, J. J. 2009. Evolutionary Biogeography. An integrative approach with case studies. Columbia University Press. New York. 301 p.

Morrone, J. J., D. Espinosa-Organista, C. Aguilar-Zúñiga y J. Llorente-Bousquets. 1999. Preliminary classification of the Mexican biogeographic provinces: A parsimony analysis of endemicity based on plant, insect, and bird taxa. Southwestern Naturalist 44:508-515.

Morrone, J. J., D. Espinosa-Organista y J. Llorente-Bousquets. 2002. Mexican biogeographic provinces: preliminary scheme, general characterizations, and synonymies. Acta Zoológica Mexicana (nueva serie) 85:83-108.

Morrone, J. J., y J. Márquez. 2001. Halffter's Mexican Transition Zone, beetle generalized tracks, and geographical homology. Journal of Biogeography 28:635-650

Morrone, J. J. y J. Márquez. 2003. Aproximación a un Atlas Biogeográfico Mexicano: componentes bióticos principales y provincias biogeográficas. In Una perspectiva latinoamericana de la biogeografía, J. J. Morrone y J. Llorente-Bousquets (eds.). Las Prensas de Ciencias, UNAM, México, D.F. p. 217-220.

Orozco-Esquivel, M. T., A. F. Nieto-Samaniego, y S. A. AlanizAlvarez. 2002. Origin of rhyolitic lavas in the Mesa Central, Mexico, by crustal melting related to extension. Journal of Volcanology and Geothermal Research 118:37-56.

Pérez-Ponce de León, G. 2003. Biodiversity and biogeographic patterns in the Mesa Central of Me'xico: insights from hostparasite systems. Journal of Parasitology 89:126-133.

Pérez-Ponce de León, G., A. Jiménez-R., B. Mendoza-Garfias, y L. García-Prieto. 2001. Helminth parasites of garter snakes and mud turtles from several localities of the Mesa Central of Mexico. Comparative Parasitology 68: 9-20.

Pérez-Ponce de León, G. y A. Choudhury. 2005. Biogeography 
of helminth parasites of freshwater fishes in México: the search for patterns and processes. Journal of Biogeography 32:645-659.

Regan, C. T. 1906-1908. Pisces. In Biologia Centrali-Americana, F. D.Godman y O. Salvin (eds.). Dulau, London. 8:1-203.

Rojas-Rabiela, T. 2004. Las cuencas lacustres del Altiplano Central. Arqueología Mexicana 68:20-27.

Schönhuth, S. y I. Doadrio. 2003. Phylogenetic relationships of Mexican minnows of the genus Notropis (Actinopterygii, Cyprinidae). Biological Journal of the Linnean Society 80:323-337.

Smith, M. L. 1980. The evolutionary and ecological history of the fish fauna of the Rio Lerma basin. Mexico. Ph.D. dissertation thesis, University of Michigan, Ann Arbor. 143 p.

Stuart, L. C. 1964. Fauna of Middle America. In Handbook of Middle America Indians, R.Wanchope y R. C. West (eds.). Handbook of Middle America Indians. University of Texas
Press, Austin. p. 316-362.

Turner, C. L. 1946. A contribution to the taxonomy and Zoogoegraphy of the Goodeid fishes. Occasional Papers of the Museum of Zoology, University of Michigan, Ann Arbor. p. 495:1-14.

Wanchope, R. y R. C. West. 1964. Natural environment and early cultures. In Handbook of Middle American Indians, R. Wanchope y R. C. West (eds.). University of Texas Press, Austin. p. 340-362.

West, R. C. 1964a. Surface configuration and asociated geology of Middle America. In R. Wanchope y R. C. West (eds.). Handbook of Middle American Indians, University of Texas Press, Austin. p. 33-82.

West, R. C. 1964b. The natural regions of Middle America. In Handbook of Middle American Indians, R. Wanchope y R. C. West (eds.). Handbook of Middle American Indians, University of Texas Press, Austin. p. 363-383. 